Research Article

\title{
Reinforcement Strain and Potential Failure Surface of Geogrid Reinforced Soil-Retaining Wall under Horizontal Seismic Loading
}

\author{
Sihan Li $\mathbb{D}^{1},{ }^{1}$ Xiaoguang Cai $\mathbb{D},^{2,3}$ Liping Jing $\mathbb{D}^{1,2}$ Honglu Xu $\mathbb{D}^{, 2,3}$ Xin Huang $\mathbb{D}^{1,2,3}$ \\ and Chen Zhu iD ${ }^{2,3}$ \\ ${ }^{1}$ Key Laboratory of Earthquake Engineering and Engineering Vibration, Institute of Engineering Mechanics, \\ China Earthquake Administration, Harbin, Heilongjiang 150080, China \\ ${ }^{2}$ College of Geological Engineering, Institute of Disaster Prevention, Sanhe, Hebei 065201, China \\ ${ }^{3}$ CEA Key Lab for Building Collapse Mechanism and Disaster Prevention, Sanhe, Hebei 065201, China
}

Correspondence should be addressed to Xiaoguang Cai; caixiaoguang123@163.com

Received 24 June 2020; Revised 14 October 2020; Accepted 19 October 2020; Published 31 October 2020

Academic Editor: Erkan Oterkus

Copyright $(92020$ Sihan Li et al. This is an open access article distributed under the Creative Commons Attribution License, which permits unrestricted use, distribution, and reproduction in any medium, provided the original work is properly cited.

\begin{abstract}
This paper presents experimental results from shaking table tests on two reduced-scale geogrid reinforced soil-retaining walls (RSRWs) constructed using standard soil, modular facing blocks, and uniaxial geogrid reinforcement to investigate the distribution of the geogrid strain and the mode of potential failure surface for dynamic loading conditions. Similitude relationships for shaking table tests in a $1 \mathrm{~g}$ gravitational field were used to scale the specimen geometry, applied characteristics of the earthquake motions. The lateral displacement of the top model is sufficiently large for the top-model block to fall down, and the RSRW is thus destroyed. The tensile strain at the lower part is greater than that at the upper part of the RSRW. The tensile strain in different layers for two-tiered RSRW is consistent with single-step RSRW. On comparing the measured maximum tensile strain lines of the geogrid with the result of the existing calculation method of the potential failure surface, it can be observed that the existing partial calculation method is conservative. Based on the calculation methods of various potential failure surfaces and the measured data, the use of a two-tiered fold-line failure surface is proposed for the two-tiered RSRW while taking into consideration the width of the platform. And it is advised that the failure surface calculation method of BS8006 be used as the calculation method for the potential failure surface of the single-step RSRW under dynamic motion.
\end{abstract}

\section{Introduction}

Reinforcement is an important part of a reinforced soilretaining wall (RSRW). To ensure the overall stability of the RSRW, the reinforcement is required to have sufficient strength and sufficient friction with the backfill. The reinforcement stress condition is the key to the internal stability analysis of the RSRW. The damage to the RSRW is caused by the destruction of the reinforcement; for instance, a RSRW collapsed owing to reinforcement corrosion in the Chile 8.2 earthquake in April of 2014 [1].

The maximum point of the internal stress of each layer of the RSRW is connected to obtain the potential failure surface of the backfill Guler and Selek [2]. The shape and location of the potential failure surface directly affects the design length of the reinforcement and the internal stability analysis of the RSRW. The existing hypothesis regarding the shape and location of the potential failure surface of the RSRW comprises four categories, which are log spiral failure surface, linear failure surface, simplified failure surface of $0.3 \mathrm{H}$, and broken line failure surface. These are presented in Figure 1.

The log spiral failure surface is a curved surface. Based on a centrifuge test, Lei [3] considered that the potential failure surface is the log spiral (Lei method) starting at the foot of the wall or the platform and reaching the rear of the top wall panel at approximately $0.169 \mathrm{H}$.

The linear failure surface is the Rankine failure surface and comprises a self-defined fitting curve. The Rankine failure surface is a plane that passes through the wall foot and the horizontal plane at an angle of $\left(45^{\circ}+\varphi / 2\right)$. The Chinese 


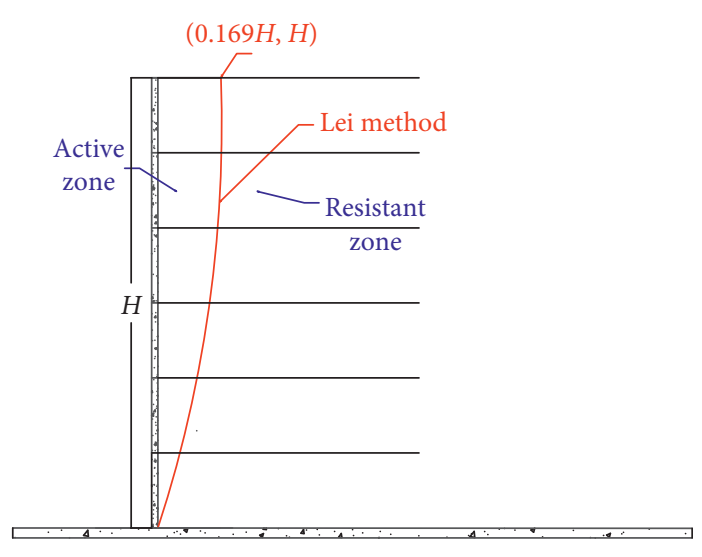

(a)

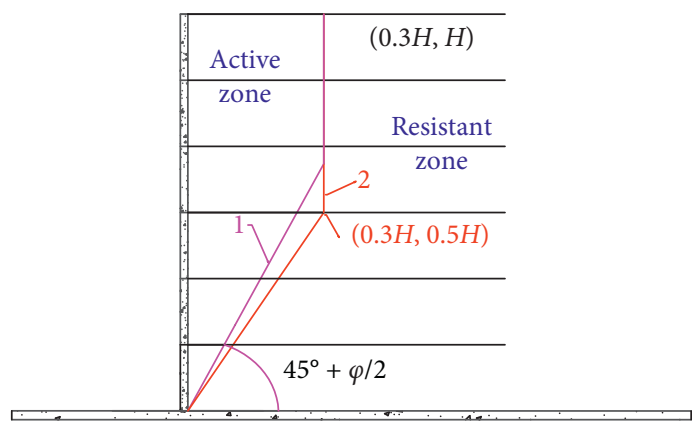

1 Highway failure surface

2 Railway failure surface

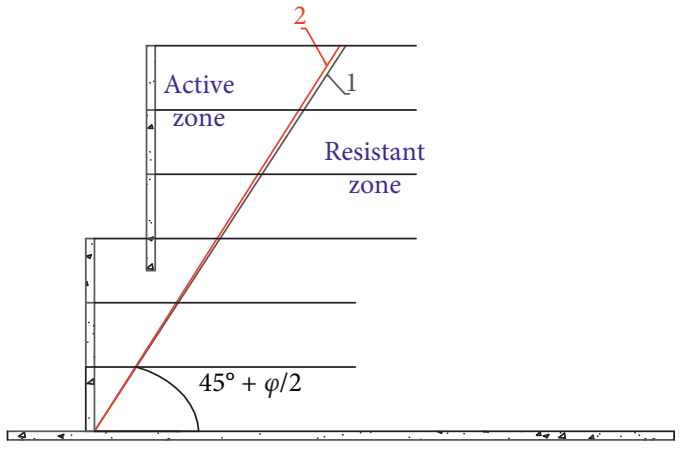

$1 \mathrm{FH}$-WA surface

2 Wang fitting curve

(b)

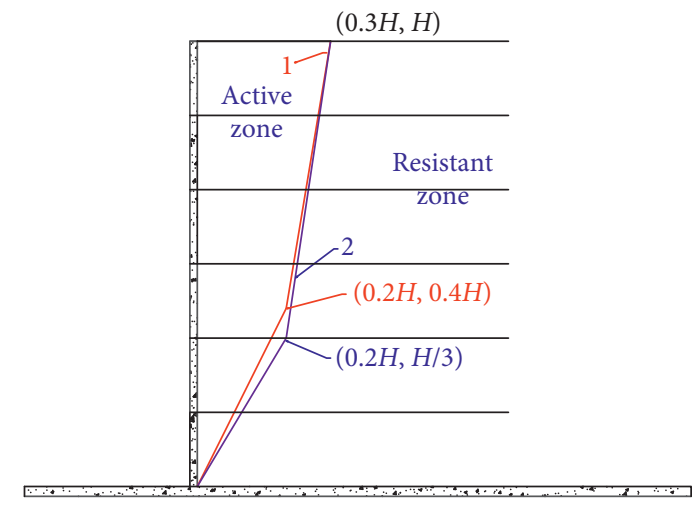

1 BS failure surface

2 New broken line type failure surface

(d)

FIGURE 1: Existing hypothesis of the potential failure surface. (a) Log spiral failure surface. (b) Linear failure surface. (c) Simplified failure surface of $0.3 H$. (d) Broken line failure surface.

Technical Code for Application of Geosynthetics (Geosynthetics) [4] and US Department of Transportation Federal Highway Administration (FHWA) [5] use the Rankine failure surface to calculate the flexible reinforcement of RSRWs. Wang and Xu [6] believe that the failure surface of a two-tiered RSRW can be approximated as a straight line $(H=-2.1452 L+14.766$, Wang fitting curve) with an angle of $\left(45^{\circ}+\varphi / 2\right)$ to the horizontal plane at the wall foot.

The simplified failure surface of $0.3 \mathrm{H}$ is used for the convenience of engineering applications. Chinese Specifications for Design of Highway Subgrades (Highway) [7] simplify the failure surface as the lower part as the wall foot $\left(45^{\circ}+\varphi / 2\right.$ to the horizontal plane), the upper part as parallel to the wall, and the upper apex as $(0.3 H, H)$; the Chinese Code for Design on Retaining Structures of Railway Subgrades (Railway) [8] and FHWA method [5] (regarding rigid reinforcement) considering that the failure surface is simplified such that it is connected to the coordinate point $(0.3 \mathrm{H}, 0.5 \mathrm{H})$ through the wall and the upper part is parallel to the wall.

The broken line failure surface is a self-defined description of the test results and specifications presented by researchers. Huang et al. [9] performed a prototype observation and numerical simulation of the gabion RSRW. They inferred that the lower part of the failure surface passes through the wall foot and the position of the breaking point $(0.2 \mathrm{H}, \mathrm{H} / 3)$ is connected to the upper point $(0.3 H, H)$ : this failure surface was named as "the new broken-line-type failure surface." Zhou et al. [10] proposed a simplified potential failure surface for an RSRW with different platform widths based on a finite element simulation; if the upper foot of the upper wall is located in the active zone of the lower wall, in the simplified potential failure surface, the lower part of the wall is the lower wall foot $D$ (platform width) $\left(45^{\circ}+\varphi / 2\right.$ with the horizontal plane). The upper part is $D+0.3 \mathrm{~h}$ from the wall ( $h$ is the height of the upper wall), upper part failure surface is parallel to the wall (Zhou surface). BS8006 [11] stipulates that the failure surface is the lower part passing through the wall foot, and the position of the broken line is $(0.2 \mathrm{H}, 0.4 \mathrm{H})$, which is connected with the upper point $(0.3 H, H)$.

The earthquake force on the RSRW is shared by the geogrid, the blocks, and the backfill (Cai et al. [12]). The acceleration has amplification effect along with the height inside the backfill (Li et al. [13]). The dynamic soil pressure increment is generated under the earthquake motion. The blocks are laterally displaced under the action of the 
earthquake. The geogrid generates strain due to the restraint of the soil and the blocks. Dynamic soil pressure and geogrid strain cause deformation, which is the external expressive from of RSRW. The limit equilibrium method is one of the applicable methods for calculating the lateral deformation of RSRW (Li et al. [14]). However, there is no unified understanding of the assumption of the failure surface. Few studies have been conducted on the internal stress and potential failure surface of reinforcement under dynamic motion. Thus, the stress and potential failure surface of the single-step RSRW and two-tiered RSRW were studied using the large-scale shaking table test. Based on the comparison of the experimental data with the results of the existing method of potential failure surface calculation, the forms of the potential failure surface suitable for the single-step RSRW and two-tiered RSRW under dynamic action are proposed. The result provides reference for the design and calculation of the geogrid RSRW.

\section{Materials and Methods}

2.1. Test Equipment. The walls were constructed in the Bidirectional Electrohydraulic Servo Seismic Simulation Shaking Table at the Civil Engineering Test Center of the Institute of Disaster Prevention. The main technical parameters of the shaking table are as follows: the table size is $3.0 \mathrm{~m} \times 3.0 \mathrm{~m}$; the bidirectional lateral seismic simulation is used; the maximum displacement is $\pm 100 \mathrm{~mm}$ in the $X$ direction and $\pm 100 \mathrm{~mm}$ in the $Y$ direction; the maximum acceleration is $2 \mathrm{~g}$ (full load) in the $X$ direction and $2 \mathrm{~g}$ (full load) in the $Y$ direction; and the maximum bearing is $20 \mathrm{t}$.

The acquisition system is mainly of two types: one is a domestic 128-channel dynamic acquisition system that can collect reinforcement strain data, the other is a domestic 16channel acceleration acquisition system that can collect table acceleration data and soil acceleration data. The model box used for the test is fabricated using steel. The size of the model box: $3.0 \mathrm{~m}$ (length) $\times 2.0 \mathrm{~m}$ (height) $\times 1.5 \mathrm{~m}$ (width), as shown in Figure 2.

2.2. Similitude Relationship. To reflect the engineering characteristics of the actual project as realistically as possible, and based on the bearing capacity of the shaking table and the size of the model box, the scaling factor of two-tiered RSRW is $1: 10$. Furthermore, the scaling factor of the singlestep RSRW is $1: 4$ and $1: 2$. However, scaling rules (Iai [15], Zheng et al. [16]) generally cannot satisfy the similarity rules for all the parameters. Therefore, it is necessary to pay attention to the main factors affecting the test results, which neglecting the secondary factors. The main scaling factors of the reduced-scale model are derived from the rules proposed by Iai [15], as listed in Table 1.

2.3. Soil. The test uses standard soil as the backfill, the relative density of which is $70 \%$. The grain composition curve of the soil is shown in Figure 3, and the physical and mechanical parameters are listed in Table 2. To strictly control the relative density, the backfill is layered and filled, and its filling method is consistent with the method used by Wang et al. [17].

2.4. Facing Wall. The production of the modular block is mainly based on the prototype of the two-tiered RSRW. The modular-block size of the prototype project is $0.60 \mathrm{~m}$ (length) $\times 0.20 \mathrm{~m}$ (width) $\times 0.25 \mathrm{~m}$ (height) and is by the scaling rules of $1: 10$. The modular-block size should be $0.060 \mathrm{~m} \quad$ (length) $\times 0.020 \mathrm{~m} \quad$ (width $) \times 0.025 \mathrm{~m} \quad$ (height) . Concerning the Guler and Selek [2] test results, the model scale of the block did not affect maximum acceleration measured on the wall. Therefore, the size of the two modular blocks used in the actual project is selected (Wang [18]): $0.25 \mathrm{~m}$ (length) $\times 0.15 \mathrm{~m} \quad$ (width) $\times 0.15 \mathrm{~m} \quad$ (height) and $0.125 \mathrm{~m} \quad$ (length) $\times 0.15 \mathrm{~m} \quad$ (width) $\times 0.15 \mathrm{~m} \quad$ (height), as shown in Figure 4. The connection between the geogrid and modular block is shown in Figure 5.

2.5. Reinforcement. A uniaxial high-density polyethene (HDPE) geogrid (Xuyu EG50\#, Qingdao, China) was used as soil reinforcement. The length of the stretching unit is $22.5 \mathrm{~cm}$. The rib spacing width is $2.22 \mathrm{~cm}$. The rib thickness is $0.1 \mathrm{~cm}$. Tensile tests were conducted on multi-rib specimens at a strain rate of $10 \% / \mathrm{min}$, according to ASTM D6637 (ASTM [19]). Results indicate that the geogrid has a tensile strength at $2 \%$ strain $T_{2 \%}=17.4 \mathrm{kN} / \mathrm{m}$ and ultimate strength $T_{\text {ult }}=50 \mathrm{kN} / \mathrm{m}$ in the machine direction. The same reinforcement was used in two reduced-scale models, and the stiffness of the geogrid in the prototype would be 100,16 , and 4 times in the scale model for $1 / 10,1 / 4$, and $1 / 2$, respectively. Reinforcement was placed with each soil lift to give a vertical spacing $S_{v}=0.15 \mathrm{~m}$. The reinforcement length of the two-tiered RSRW is $0.9 \mathrm{~m}$, which length selected according to the prototype project. At the same time, the reinforcement length of the single-step RSRW is $1.26 \mathrm{~m}$, which length selected from other literature (Ling et al. [20]; Guler and Selek, [2]). The model design of the RSRW, refer to the chosen measured-point-position of strain gauges, is shown in Figure 6.

2.6. Instrumentation. The model design diagrams of specimens are shown in Figure 6. Specimen 1 shows the model of the two-tiered RSRW, wherein the total height is $1.8 \mathrm{~m}$, and the platform width is $0.18 \mathrm{~m}$. A total of 104 strain gauges are placed to observe the dynamic strain of the geogrid. There are four layers on the East side, which are $F 1, F 5, F 6$, and $F 7$. Each layer is arranged with four positions, and each position is arranged on the upper side. A total of 11 layers are arranged on the West side, each layer is arranged with four positions, and each position has a strain gauge on each of the top and bottom, to correct for bending Bathurst et al. [21].

Specimen 2 shows the model of the single-step RSRW; with a total height of $1.8 \mathrm{~m}$. A total of 88 strain gauges are arranged. To obtain more accurate measures data, the strain gauges are mounted on the top and bottom in the $F 1, F 2$, and $F 3$ geogrids, and the top and bottom of the four measured points away from the panel in the $F 5, F 6$, and $F 7$ layers. 


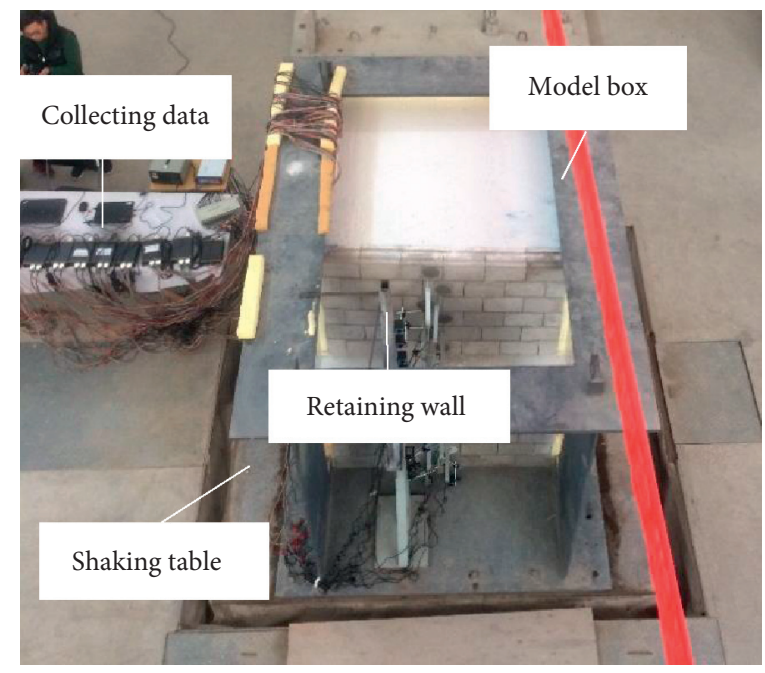

FIgURe 2: Model test equipment.

TABLE 1: Scaling factors in model test.

\begin{tabular}{|c|c|c|c|c|c|}
\hline \multirow{2}{*}{ Number } & \multirow{2}{*}{ Physical quantity } & \multirow{2}{*}{ Similarity constants } & \multirow{2}{*}{$\begin{array}{l}\text { Two-tiered RSRW } \\
\qquad 1: 10\end{array}$} & \multicolumn{2}{|c|}{ Single-step RSRW } \\
\hline & & & & $1: 2$ & $1: 4$ \\
\hline 1 & Length $(L)$ & $C_{1}$ & 10 & 2 & 4 \\
\hline 2 & Elastic modulus $(E)$ & $C_{e}=1$ & 1 & 1 & 1 \\
\hline 3 & Density $(\rho)$ & $C_{\rho}=1$ & 1 & 1 & 1 \\
\hline 4 & Stress $(\sigma)$ & $C_{\sigma}=C_{e}=1$ & 1 & 1 & 1 \\
\hline 5 & Time $(t)$ & $C_{t}=C_{l}^{0.5}$ & 3.16 & 1.414 & 2 \\
\hline 6 & Velocity $(v)$ & $C_{v}=C_{l}^{0.5}$ & 3.16 & 1.414 & 2 \\
\hline 7 & Acceleration $(a)$ & $C_{a}=1$ & 1 & 1 & 1 \\
\hline 8 & Gravity $(g)$ & $C_{g}=1$ & 1 & 1 & 1 \\
\hline 9 & Frequency $(\omega)$ & $C_{\omega} \stackrel{g}{=} C_{l}^{-0.5}$ & 0.316 & 0.707 & 0.5 \\
\hline
\end{tabular}

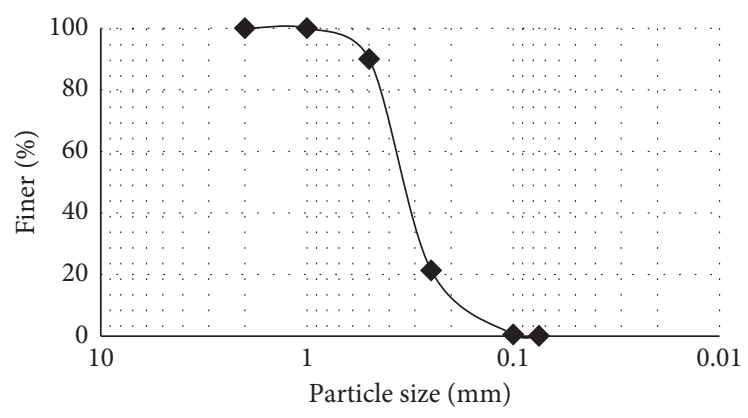

FIgURE 3: Grain composition curve of the soil.

TABLE 2: Physical and mechanical parameters of filling.

\begin{tabular}{lcccccc}
\hline $\begin{array}{l}\text { Characteristic } \\
\text { particle size }(\mathrm{mm})\end{array}$ & Nonuniform coefficient & Curvature coefficient & Maximum dry density $\left(\mathrm{g} / \mathrm{cm}^{3}\right)$ & Internal friction angle $\left(^{\circ}\right)$ \\
\hline $\mathrm{d}_{60}$ & $\mathrm{~d}_{30}$ & $\mathrm{~d}_{10}$ & $\mathrm{C}_{u}$ & $\mathrm{C}_{c}$ & $\rho_{d}$ & $\varphi$ \\
0.37 & 0.29 & 0.18 & 2.055 & 1.262 & 1.82 & 41 \\
\hline
\end{tabular}




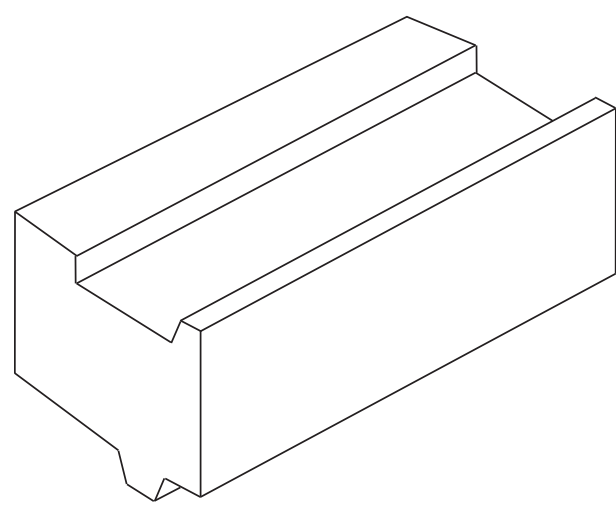

(a)

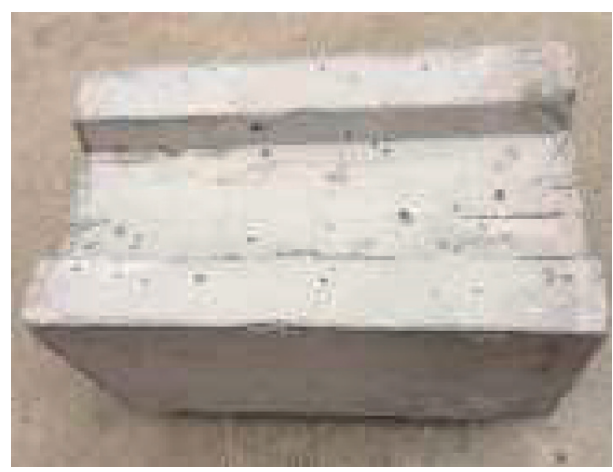

(c)

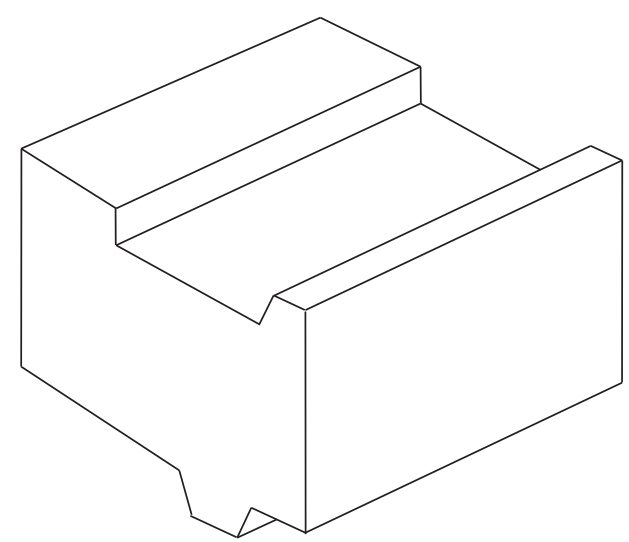

(b)

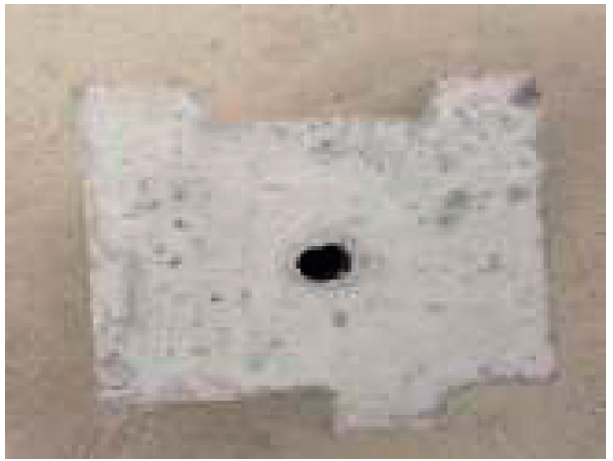

(d)

Figure 4: Modular block. (a) Block sample 1. (b) Block sample 2. (c) Model block front. (d) Model block side.

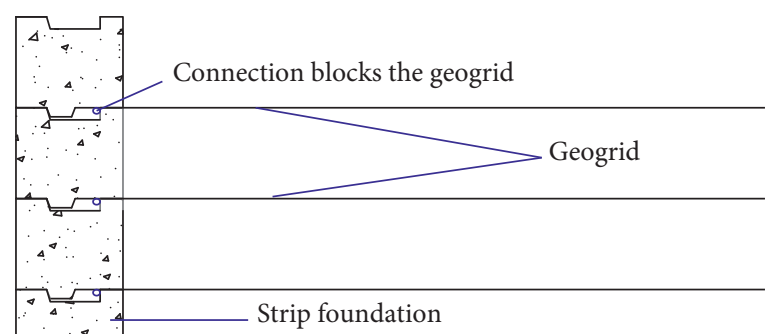

FIGURE 5: Connection between geogrid and block.

2.7. Input Motions. To further understand the failure mechanism of the modular block RSRW and identify the failure phenomenon, and obtain the critical strains, the input acceleration is gradually increased until the retaining wall is damaged. Wolong wave (WL) was recorded in Wolong station during the Wenchuan earthquake in China in 2008, and the EL-Centro motion (EL) was recorded in ELCentro station during the Imperial Valley earthquake in the USA in 1940. The peak acceleration of the WL is $1.0 \mathrm{~g}$, and the time interval of the data points is $0.005 \mathrm{~s}$. The peak acceleration of the EL is $1.0 \mathrm{~g}$. and the time interval of the data points is $0.02 \mathrm{~s}$. The duration time is $58.5 \mathrm{~s}$. The time and peak acceleration may be adjusted and compressed. The acceleration time history and Fourier spectra are presented in Figure 7.

The tests are performed in the order of the peak acceleration from small to large, and the time compression ratio of specimen 2 is from high to low. Each time white noise is applied in between each seismic motion during specimen 1. White noise is input before and after each change in motion magnitude for specimen 2 . The loading cases are listed in Tables 3 and 4. 


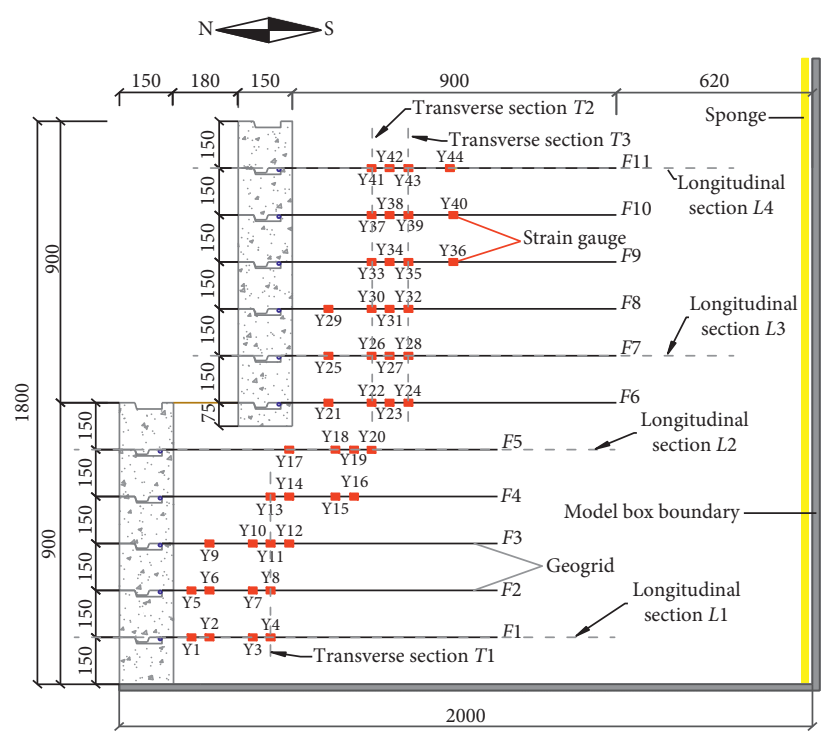

- Strain gauge

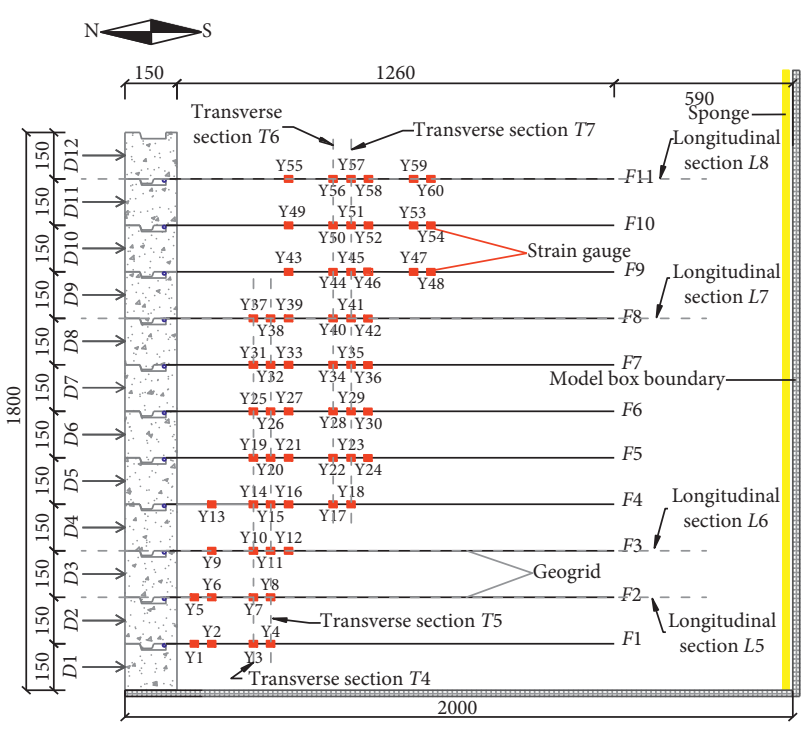

- Strain gauge

(a)

(b)

Figure 6: Shaking table model of RSRW. (a) Specimen 1. (b) Specimen 2.

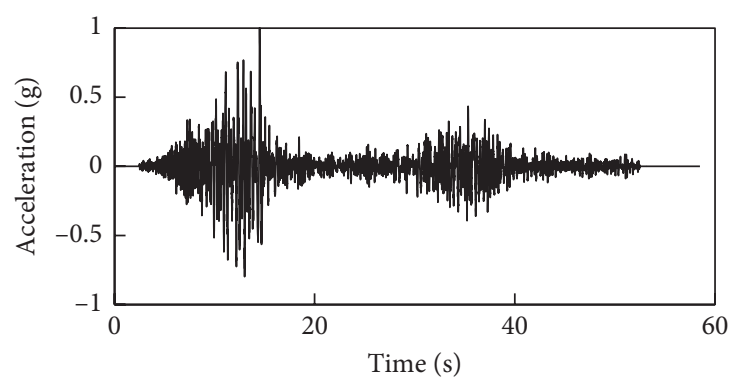

(a)

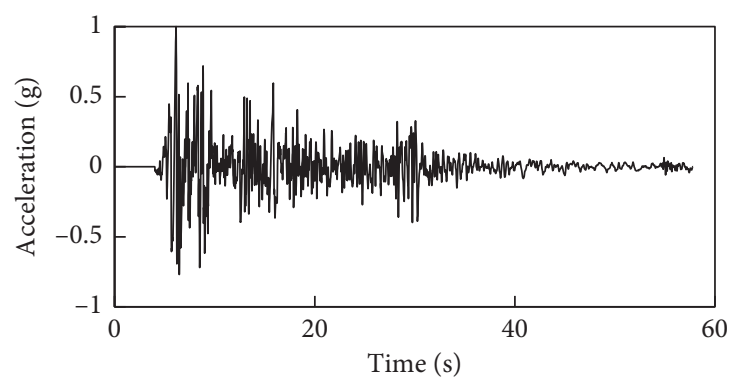

(c)

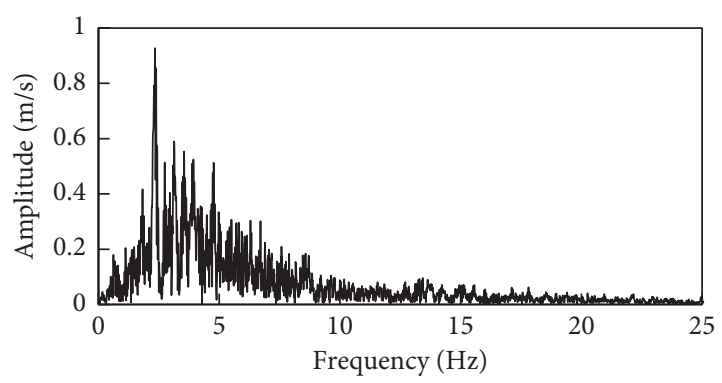

(b)

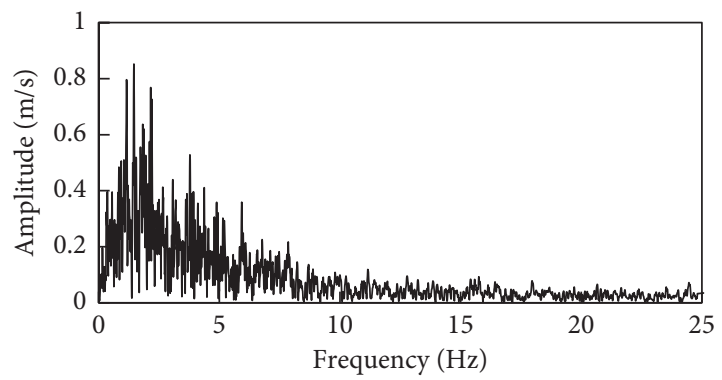

(d)

Figure 7: Time history of earthquake motion and fourier spectra. (a) WL. (b) WL fourier spectra. (c) EL. (d) EL fourier spectra.

After each loading case, data viewing, recording of the damage outside the specimens, photographing, and other related works are performed. All the acquisition channels are then zeroed, and the model is treated as a new model for the next case until the model is destroyed.

\section{Results and Discussion}

3.1. Model Damage Phenomena. As the damage mode of the specimens 1 and 2, the top model blocks falls, and the model is destroyed, as shown in Figure 8. The specimen 1 is 
TABLE 3: Loading cases of specimen 1.

\begin{tabular}{lcccc}
\hline Case number & Input wave & PGA (g) & Model scale & Case code \\
\hline \multirow{2}{*}{1} & White Noise & 0.05 & 1 & WN \\
& WL & 0.2 & 10 & WL0.2 g \\
\hline \multirow{2}{*}{2} & White Noise & 0.05 & 1 & WN \\
& EL & 0.2 & 10 & EL0.2 g \\
\multirow{2}{*}{3} & White Noise & 0.05 & 1 & WN \\
& WL & 0.4 & 10 & WL0.4 g \\
\multirow{2}{*}{4} & White Noise & 0.05 & 1 & WN \\
& EL & 0.4 & 10 & EL0.4 g \\
\multirow{2}{*}{5} & White Noise & 0.05 & 1 & WN \\
& WL & 0.8 & 10 & WL0.8 g \\
\multirow{2}{*}{6} & White Noise & 0.05 & 1 & WN \\
& EL & 0.8 & 10 & EL0.8 g \\
\multirow{2}{*}{7} & White Noise & 0.05 & 1 & WN \\
& WL & 1.2 & 10 & WL1.2 g \\
\multirow{2}{*}{8} & White Noise & 0.05 & 1 & WN \\
& EL & 1.2 & 10 & EL1.2 g \\
\multirow{2}{*}{9} & White Noise & 0.05 & 1 & WN \\
& WL & 1.6 & 10 & WL1.6 g \\
\hline
\end{tabular}

destroyed in Case 9, as shown in Figure 8(a). The specimen 2 is destroyed in Case 32, as shown in Figure 8(b). It is a very well known facing stability issue; the falling of the top block has nothing to do with the stability of the wall. Therefore, the top two or three blocks are always connected rigidly both in practice and in research to avoid this type of top block failing Guler and Selek [2].

3.2. Geogrid Strain of Specimen 1. Figure 9 shows the strain time history of the F6 layer Y21 under Case 3. Part of the strain time history is selected and divided into two parts for analysis, which includes the horizontal same-layer comparison and vertical same position comparison.

3.2.1. Horizontal Same-Layer Comparison. Figure 10 shows the strain curve of longitudinal section $L 1, L 2, L 3$, and $L 4$ under different peak accelerations.

In general, the strain values of the strain points in each layer increase with the increase in the peak acceleration motion. When the peak acceleration is small, the strain values of different points are almost the same, and the strain trend approximates a straight line. The strain growth of each strain point is different, and the strain trend gradually changes into a curve with the acceleration increase. There is a difference under WL1.6 $\mathrm{g}$ that the strain values under WL $1.6 \mathrm{~g}$ are smaller than those under WL $1.2 \mathrm{~g}$. The reason is the top blocks fall under WL $1.6 \mathrm{~g}$, resulting in a reduction in the tensile force of the reinforcement. The strain trends of the $L 1$ and $L 2$ layers of the lower wall are one maximum (minimum) value and are consistent with the strain trend of the $L 3$ and $L 4$ layers of the upper wall. During the increase in the peak acceleration, the maximum strain of the $L 1$ layer gradually approaches $Y 3$, the maximum strain of the $L 3$ layer gradually moves closer to $Y 28$, and the maximum strain of the $L 4$ layer gradually approaches $Y 44$. It can be inferred that
TABle 4: Loading cases of specimen 2.

\begin{tabular}{|c|c|c|c|c|}
\hline $\begin{array}{l}\text { Case } \\
\text { number }\end{array}$ & $\begin{array}{l}\text { Input } \\
\text { wave }\end{array}$ & $\begin{array}{c}\text { PGA } \\
(\mathrm{g})\end{array}$ & $\begin{array}{l}\text { Model } \\
\text { scale }\end{array}$ & Case code \\
\hline & $\begin{array}{l}\text { White } \\
\text { noise }\end{array}$ & 0.05 & 1 & WN \\
\hline 1,2 & WL, EL & 0.1 & 4 & $\begin{array}{l}\text { WL0.1 g, } \\
\text { EL0.1 g }\end{array}$ \\
\hline \multirow[t]{2}{*}{3,4} & WL, EL & 0.1 & 2 & WL0.1 g, EL0.1 g \\
\hline & $\begin{array}{l}\text { White } \\
\text { noise }\end{array}$ & 0.05 & 1 & WN \\
\hline 5,6 & WL, EL & 0.2 & 4 & WL0.2 g, EL0.2 g \\
\hline \multirow[t]{2}{*}{7,8} & WL, EL & 0.2 & 2 & WL0.2 g, EL0.2 g \\
\hline & $\begin{array}{l}\text { White } \\
\text { noise }\end{array}$ & 0.05 & 1 & WN \\
\hline 9,10 & WL, EL & 0.4 & 4 & WL0.4 g, EL0.4 g \\
\hline \multirow[t]{2}{*}{11,12} & WL, EL & 0.4 & 2 & WL0.4 g, EL0.4 g \\
\hline & $\begin{array}{l}\text { White } \\
\text { noise }\end{array}$ & 0.05 & 1 & $\mathrm{WN}$ \\
\hline 13,14 & WL, EL & 0.6 & 4 & WL0.6g, EL0.6g \\
\hline \multirow[t]{2}{*}{15,16} & WL, EL & 0.6 & 2 & WL0.6g, EL0.6 g \\
\hline & $\begin{array}{l}\text { White } \\
\text { noise }\end{array}$ & 0.05 & 1 & WN \\
\hline 17,18 & WL, EL & 0.8 & 4 & WL0.8g, EL0.8 g \\
\hline \multirow[t]{2}{*}{19,20} & WL, EL & 0.8 & 2 & WL0.8 g, EL0.8 g \\
\hline & $\begin{array}{l}\text { White } \\
\text { noise }\end{array}$ & 0.05 & 1 & $\mathrm{WN}$ \\
\hline 21,22 & WL, EL & 1.0 & 4 & WL1.0g, EL1.0 g \\
\hline \multirow[t]{2}{*}{23,24} & WL, EL & 1.0 & 2 & WL1.0 g, EL1.0 g \\
\hline & $\begin{array}{l}\text { White } \\
\text { noise }\end{array}$ & 0.05 & 1 & $\mathrm{WN}$ \\
\hline 25,26 & WL, EL & 1.2 & 4 & WL1.2 g, EL1.2 g \\
\hline \multirow[t]{2}{*}{27,28} & WL, EL & 1.2 & 2 & WL1.2 g, EL1.2 g \\
\hline & $\begin{array}{l}\text { White } \\
\text { noise }\end{array}$ & 0.05 & 1 & $\mathrm{WN}$ \\
\hline 29 & WL & 1.6 & 4 & WL1.6g \\
\hline \multirow[t]{2}{*}{30} & WL & 1.6 & 2 & WL1.6g \\
\hline & $\begin{array}{l}\text { White } \\
\text { noise }\end{array}$ & 0.05 & 1 & $\mathrm{WN}$ \\
\hline 31 & WL & 2.0 & 4 & WL2.0 g \\
\hline 32 & WL & 2.0 & 2 & $\mathrm{WL} 2.0 \mathrm{~g}$ \\
\hline
\end{tabular}

the maximum strain point of each layer expands toward the interior of the soil as the acceleration increases.

3.2.2. Vertical Same Position Comparison. Figure 11 shows the distribution of the geogrid strain values of the lower retaining wall transverse section $T 1$ along with the height of the wall. As can be observed from the figure, the strain value increases with the acceleration increase, and the maximum value is observed at $F 2$. Figure 12 shows the distribution of the geogrid strain values of the upper retaining wall $T 2$ and T3 along with the height of the wall. It can be observed from Figure 12 that the strain value increases with the increase in the acceleration. On comparing the Figures 12(a) and 12(b), the distance from the retaining wall is different, and the distributions of the strain are different. The strain at $T 2$ has maximum values at $F 7(105 \mathrm{~cm})$ and $F 9(135 \mathrm{~cm})$, and a minimum value at $F 8(120 \mathrm{~cm})$; the strain at $T 3$ has maximum values at $F 7(105 \mathrm{~cm})$ and $F 10(150 \mathrm{~cm})$, and a minimum value at $F 9(135 \mathrm{~cm})$. 


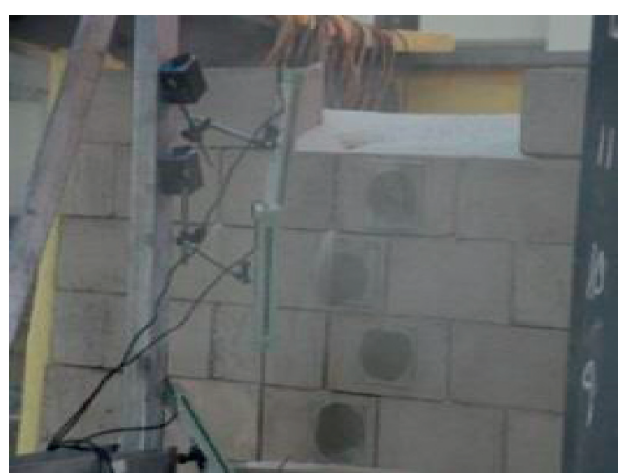

(a)

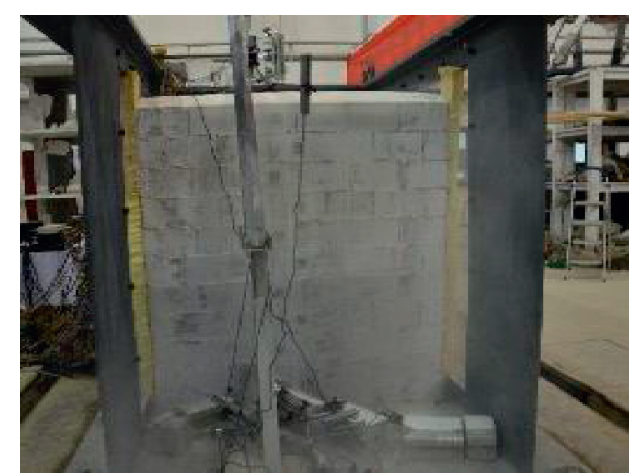

(b)

FIgURE 8: Seismic damage to RSRW. (a) Specimen 1 damage. (b) Specimen 2 damage.

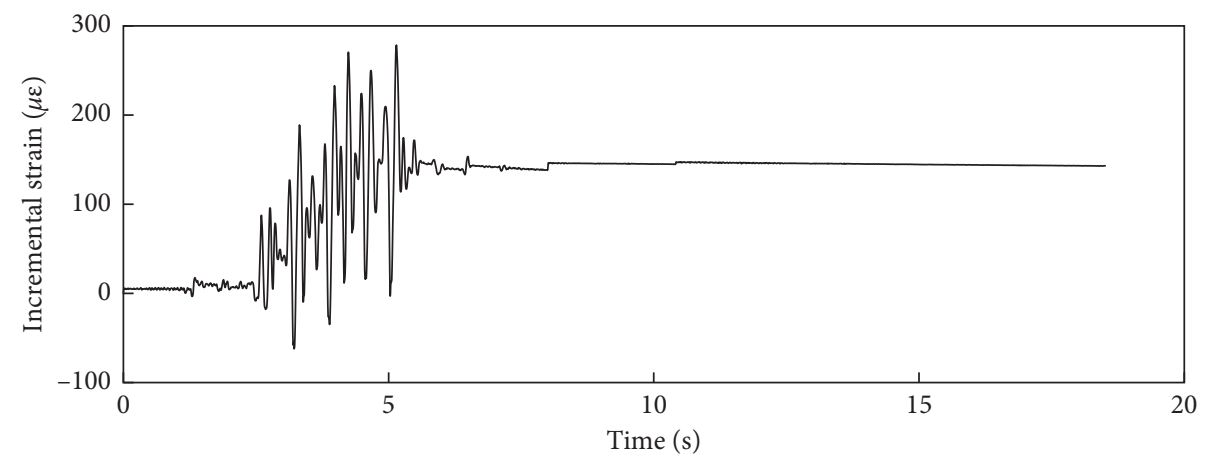

FIgURE 9: Time history of geogrid strain for specimen 1 under case 3.

3.3. Geogrid Strain of Specimen 2. Figure 13 shows the strain time history of the Y53 under cases 13 and 14. Part of the strain time history is selected and divided into two parts for analysis, and these comprise the horizontal same-layer comparison and vertical same position comparison.

3.3.1. Horizontal Same-Layer Comparison. Figures 14 and 15 show the strain curve of longitudinal sections $L 5, L 6, L 7$, and $L 8$ under the WL and EL (model scale: $1 / 4$ ).

As can be observed from Figures 14 and 15, the strain at each strain point of each layer increases as the acceleration increases. The strain values of each layer are different, but the trend of the same-layer strain is consistent under different peak accelerations. When the peak acceleration is small, the strain values of the strain points are almost the same, and the strain trend line approximates a straight line. The higher the geogrid layer in the retaining wall, the less the trend line of the strain will approximate a straight line. The strain growth of each strain point is different, and the trend line gradually changes into an oblique line or curve with the increase in the peak acceleration. The strain values of the various strain points in each layer are also different under different cases.

On comparing the reinforcement strain of different layers, it can be observed that the reinforcement strain value of the lower wall is greater than that of the upper wall. The strain trend is consistent with the trend of the specimen 1. This condition may be caused by the fact that the reinforcement of the different layers bears different vertical pressures.

3.3.2. Vertical Same Position Comparison. Figure 16 shows the distribution of the strain values at transverse section T4 and $T 5$ under the WL and the EL (model scale: 1/4); Figure 17 shows the distribution of the strain values at $T 6$ and T7 under the WL and EL (model scale: 1/4).

It can be observed from Figures 16 and 17, the strains values at the same position of different layers increase with the acceleration increase. When the similarity ratio and seismic motion are consistent, the distributions of the strain values at the same position $(T 4, T 5, T 6$, and $T 7)$ are nearly identical. The strain law at T4 under WL $0.1 \mathrm{~g}-\mathrm{WL} 1.6 \mathrm{~g}$ (model scale: $1 / 4)$ that there are two maximum points $(F 3$ $(45 \mathrm{~cm})$ and $F 7(105 \mathrm{~cm}))$ and one minimum point $(F 5$ $(75 \mathrm{~cm}))$. Moreover, the strain laws are nearly the same under different working cases (comparison of T4 with T5, and $T 6$ with T7). The strain laws at $T 4$ and $T 5$ both have a maximum point $(F 3(45 \mathrm{~cm}))$ and a minimum point $(F 5$ $(75 \mathrm{~cm})$ ) under the EL (model scale: $1 / 4$ ).

When the model scale is consistent, and the seismic waves are different, the strain laws at the same position are slightly different. When the model scale is $1: 4$, the strain trend has two maximum points $(F 3(45 \mathrm{~cm})$ and $F 7$ $(105 \mathrm{~cm}))$ and one minimum point $(F 5(75 \mathrm{~cm}))$ under the $\mathrm{WL}$, while the strain trend has just one maximum point ( F3 


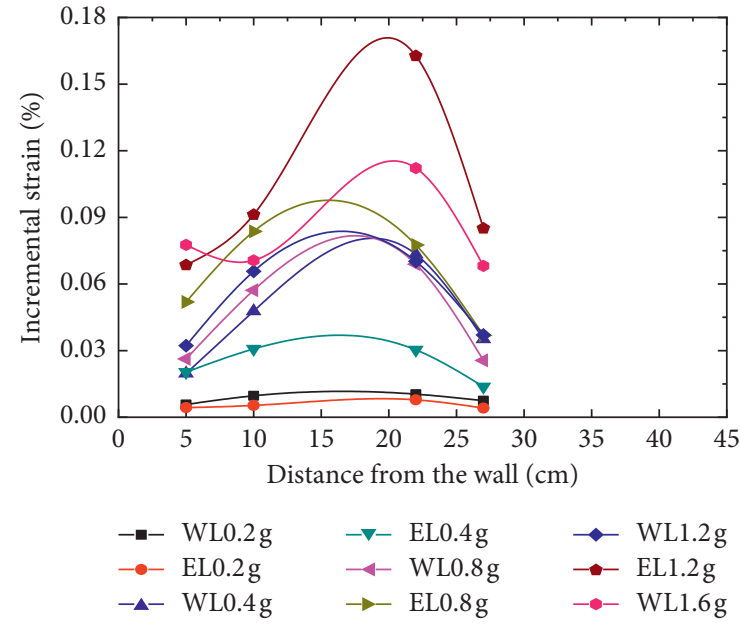

(a)
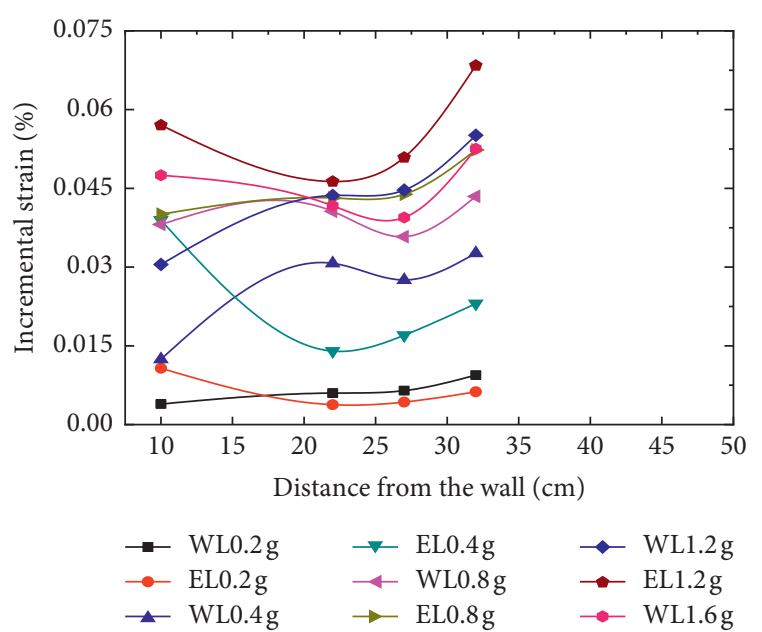

(c)

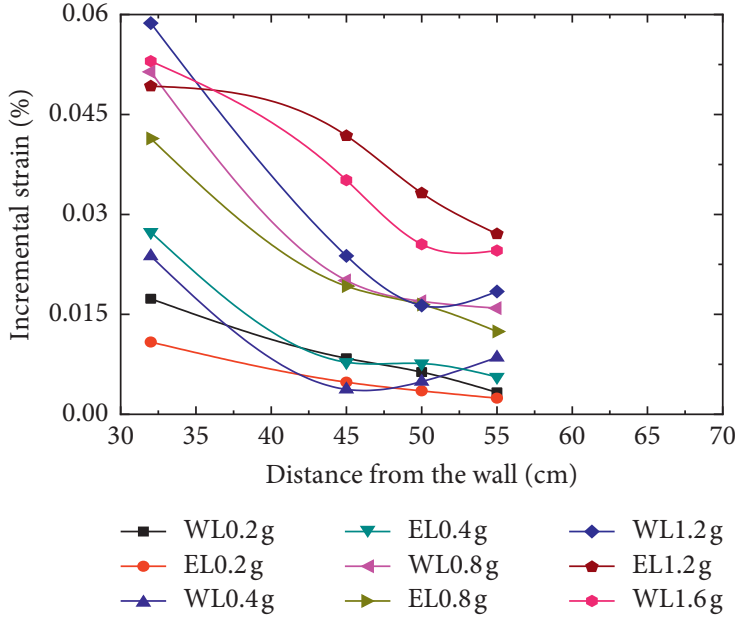

(b)

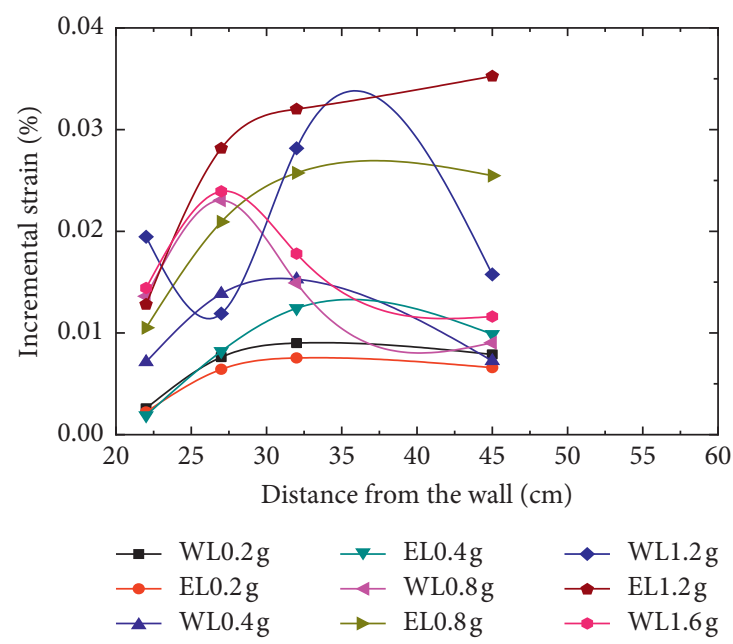

(d)

Figure 10: Distributions of strain in different layers for specimen 1. (a) L1. (b) L2. (c) L3. (d) L4.

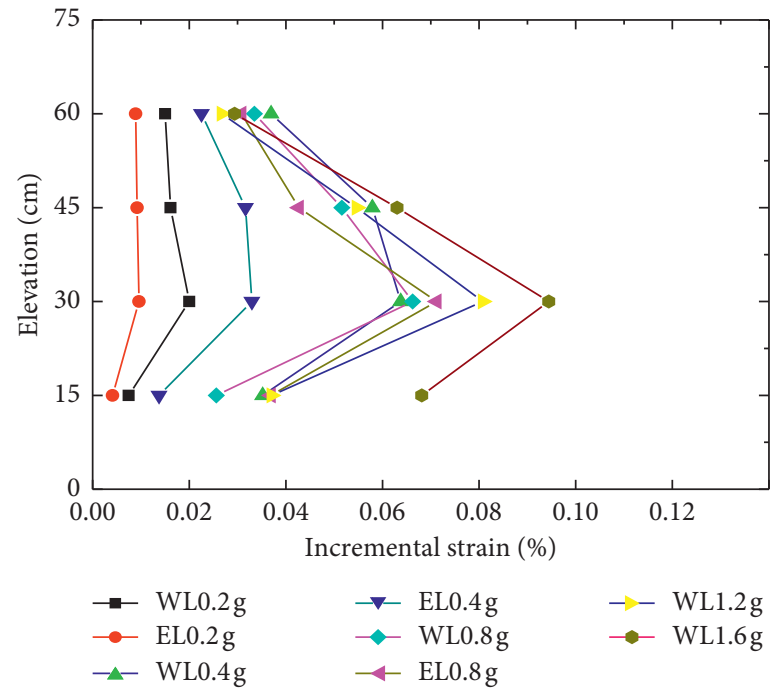

FIgURE 11: Distributions of strain in $T 1$ for specimen 1. 


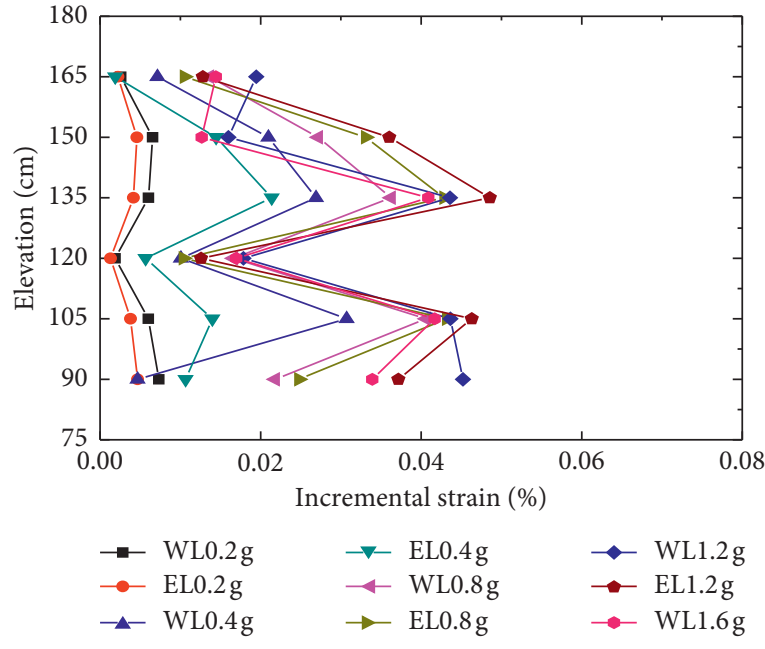

(a)

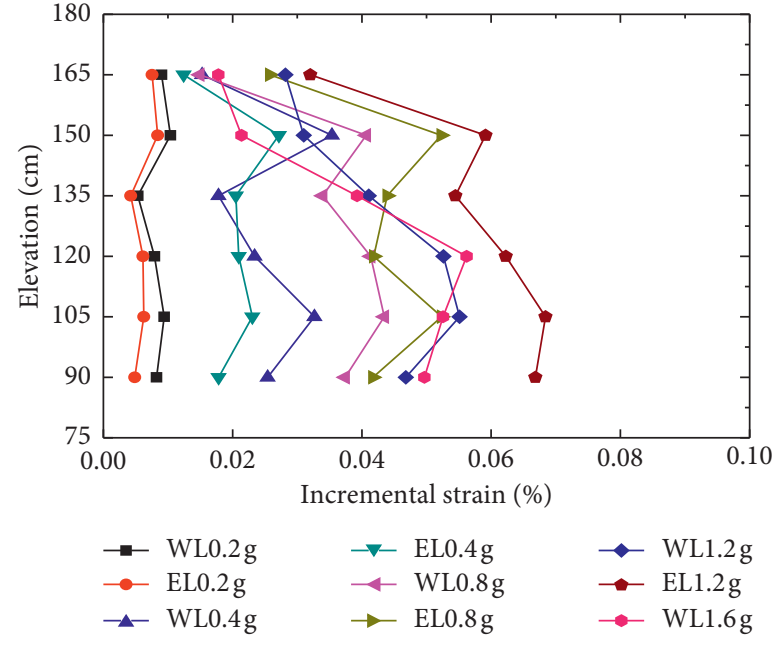

(b)

Figure 12: Distributions of strain in $T 2$ and $T 3$ for specimen 1. (a) $T 2$. (b) $T 3$.

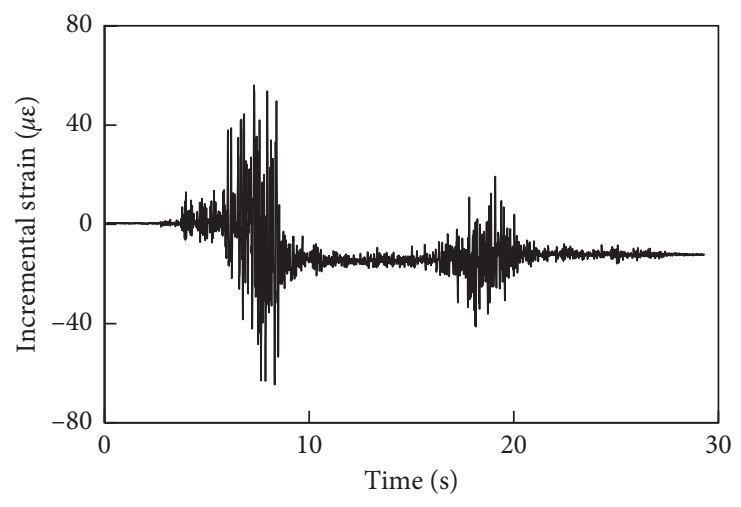

(a)

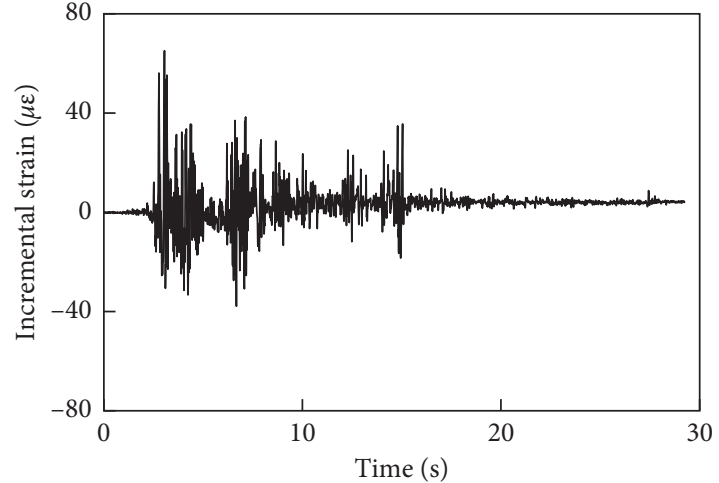

(b)

Figure 13: Time history of geogrid strain for specimen 2. (a) Case 13. (b) Case 14.

$(45 \mathrm{~cm}))$ and one minimum point $(F 5(75 \mathrm{~cm}))$ under the EL. This may be caused by different types of seismic motions.

3.4. The Curve of the Potential Failure Surface. On taking the strain curve of each layer of the specimen 2 as an example, the maximum strain point of each layer of the specimen 2 under cases 31 and 32 are connected in a curve, and the curve is compared with the $0.3 \mathrm{H}$ simplified failure surface of the Railway Code [8]. It can be observed that the $0.3 \mathrm{H}$ simplified failure surface is conservative, as shown in Figure 18.

3.5. Potential Failure Surface Calculation Method for Specimen 1. The index fitting of the measured strain curve of the specimen 1 is shown in Figure 19. It can be observed that the position of the potential failure surface gradually expands toward the interior of the soil as the acceleration increases.

As for the design method of the multitiered RSRW, only the FHWA [5] and the National Concrete Masonry Association (NCMA) [22] guideline of the U.S are based on different assumptions, and only the design method of the two-tiered RSRW is simply specified. FHWA's [5] design method is as follows: (1) For a small upper wall offset; $D \leq 1 / 20(H 1+H 2)$ (the definition of the wall heights: $H_{1}$ is the upper wall height, $H_{2}$ is the lower wall height, and $D$ is the offset distance), it is assumed that the failure surface does not fundamentally change, and it is simply adjusted laterally using the offset distance $D$. The walls should be designed as a single wall of height $H$. (2) When $\mathrm{D}$ is greater than $\mathrm{H}_{2} \tan \left(90^{\circ}-\varphi\right)$, the walls are not considered to be superimposed and are independently designed from an internal stability viewpoint. (3) Only when $(H 1+H 2) / 20 \leq D \leq H 2$ tan $\left(90^{\circ}-\varphi\right)$, the internal and external stability calculation of the lower wall are required to be performed by considering the influence of the upper wall load on the vertical pressure of the lower wall. However, the design method of the multitiered RSRW is not explained. The NCMA method stated that the interaction of the upper and lower adjacent walls is not considered in the design of the upper wall, and the upper 


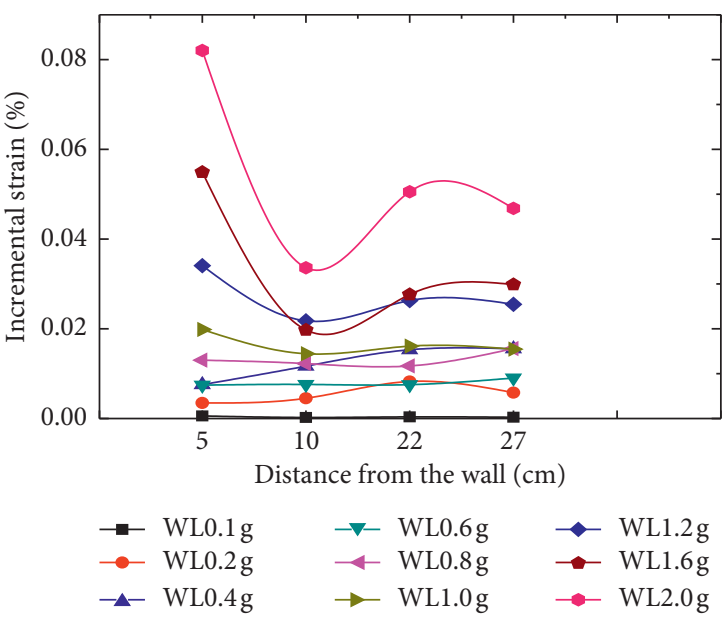

(a)

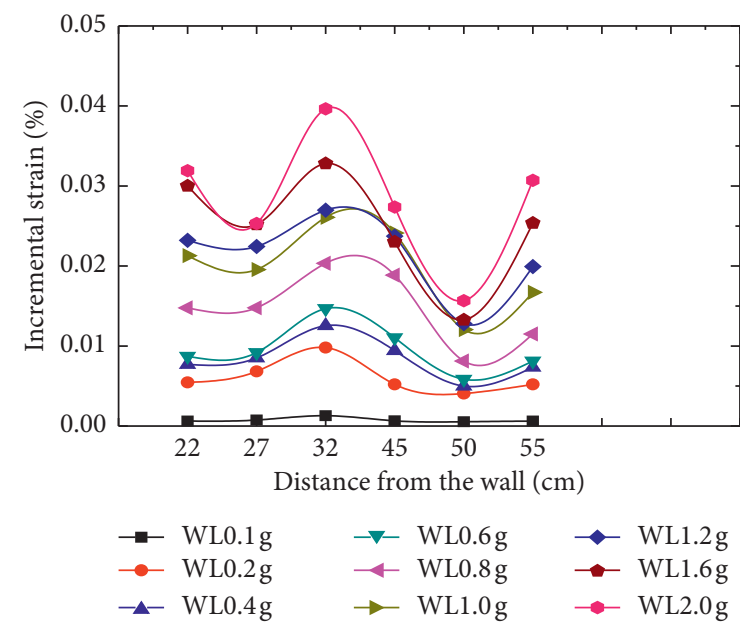

(c)

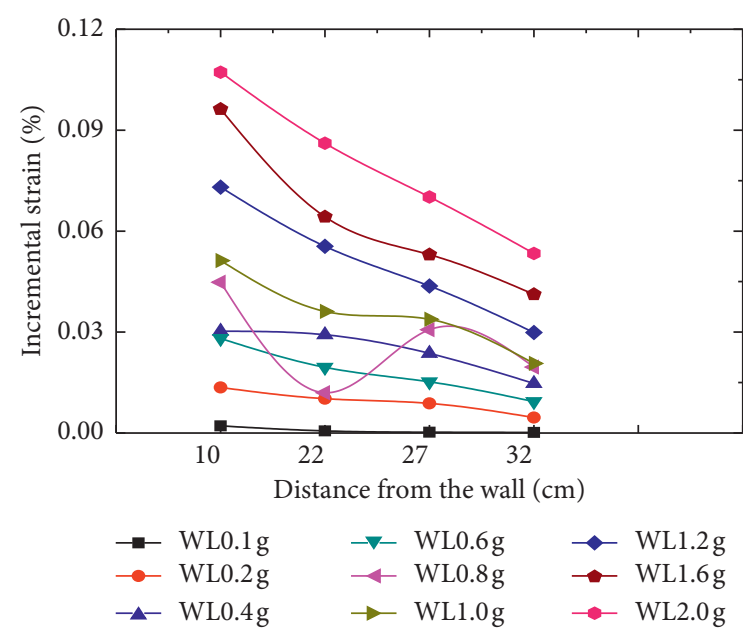

(b)

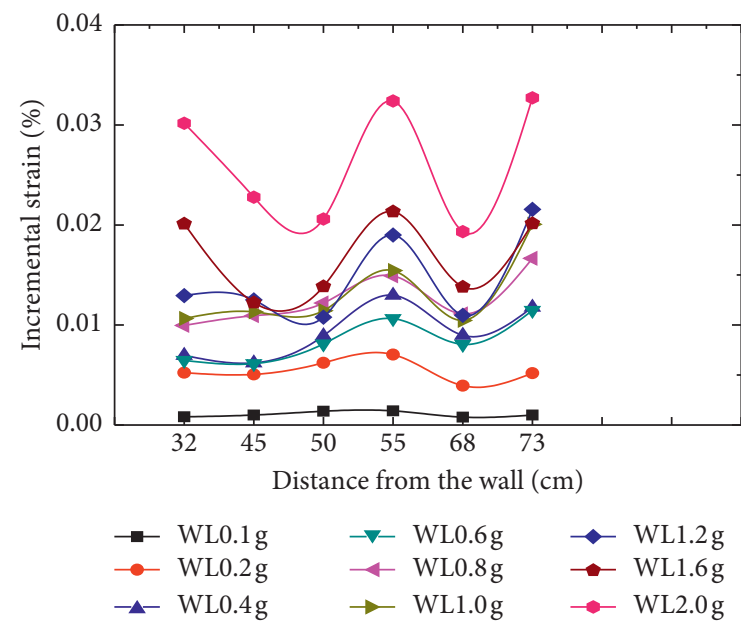

(d)

FIgURe 14: Distributions of strain in reinforcement layers for specimen 2 under WL (model scale: 1/4). (a) L5. (b) L6. (c) L7. (d) L8.

wall should be equivalent to the top outside uniformly external load of the retaining wall when designing the lower wall.

According to the FHWA calculation method, the offset width of the specimen 1 is $0.18 \mathrm{~m}$, which is in the stage of $(H 1+H 2) / 20 \leq D \leq H 2 \tan \left(90^{\circ}-\varphi\right)$. The various methods of calculating the potential failure surface are summarized in Figure 20. Although some methods (the FHWA method, Wang fitting curve, and Zhou simplify potential failure surface) can be used as the simplify potential failure surface at $\left(H_{1}+H_{2}\right) / 20 \leq D \leq H_{2} \tan \left(90^{\circ}-\varphi\right)$ stage of specimen 1 . Considering the engineering cost, the use of a two-tiered fold-line potential failure surface is proposed for the twotiered RSRW at the $\left(H_{1}+H_{2}\right) / 20 \leq D \leq H_{2} \tan \left(90^{\circ}-\varphi\right)$ stage.

For the two-tiered fold-line potential failure surface, it is assumed that the lower part passes through the wall foot, and the wall foot is used as the origin to establish the coordinate axis of the RSRW. The wall height is the independent variable $y$, and the failure surface position is the dependent variable $x$. The failure surface formula is as follows:

$$
\begin{aligned}
& x=\frac{0.3 h_{u}+D+d}{h_{l}} * y, \quad y \in\left[0, h_{l}\right), \\
& x=\frac{D}{h_{u}} * y+B, \quad y \in\left[h_{l}, h_{l}+h_{u}\right], \\
& B=\frac{D\left(h_{u}-h_{l}\right)+h_{u} d+0.3 h_{u}^{2}}{h_{u}},
\end{aligned}
$$

where $D$ is the platform width; $d$ is the thickness of the wall, $h_{l}$ is the height of lower wall, and $h_{u}$ is the height of the upper wall.

The line type 9 is added in Figure 21; it can better react the failure surface of the two-tiered RSRW at $\left(H_{1}+H_{2}\right) /$ $20 \leq D \leq H_{2} \tan \left(90^{\circ}-\varphi\right)$ stage. 


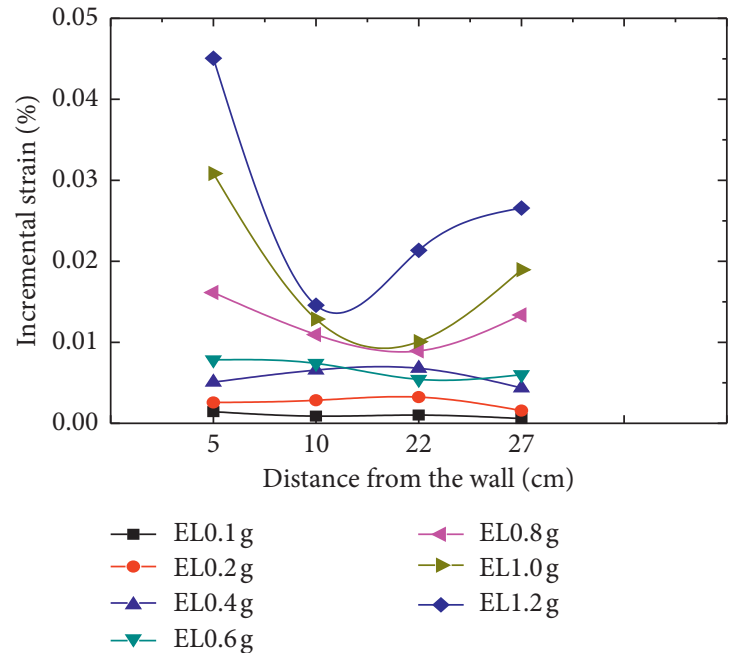

(a)

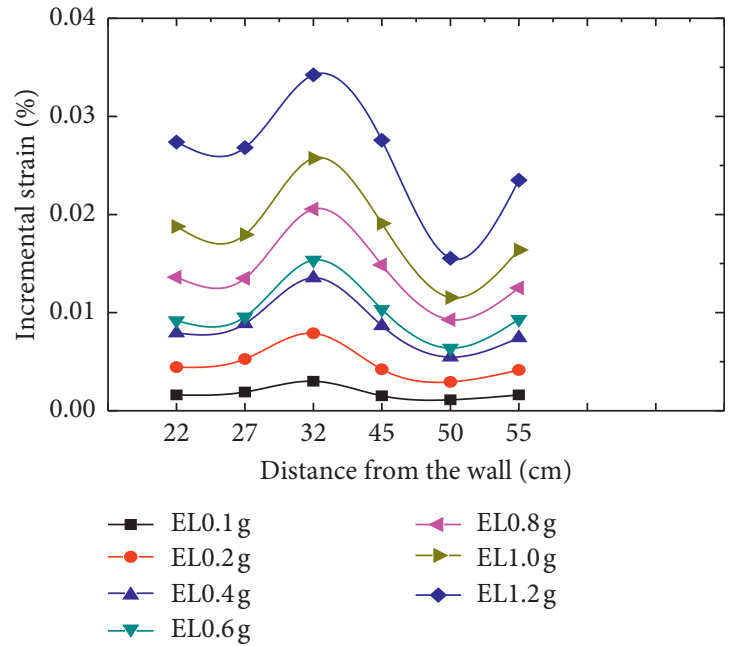

(c)

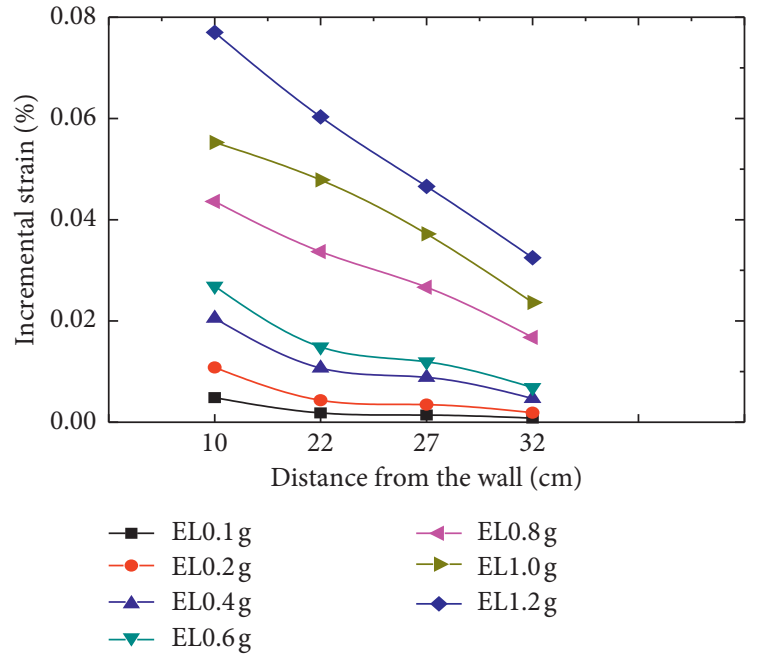

(b)

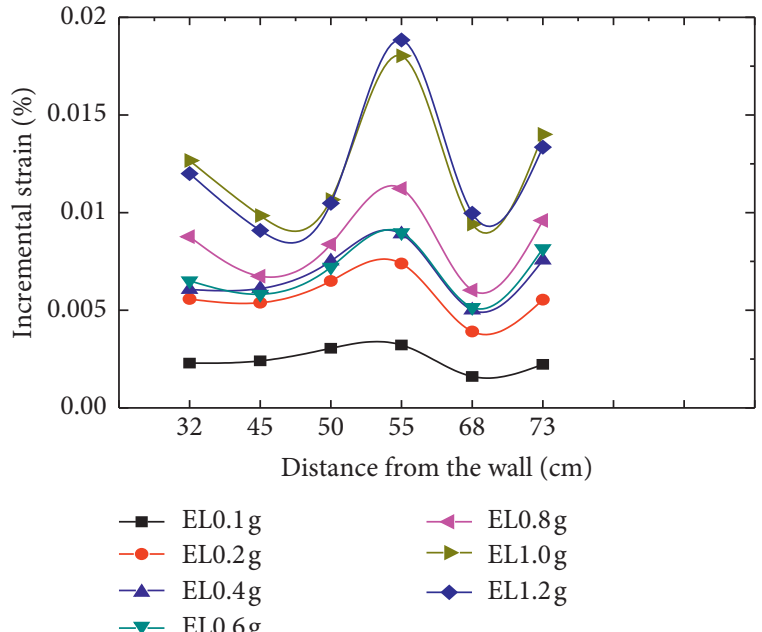

(d)

FIGURE 15: Distributions of strain in reinforcement layers for specimen 2 under EL (model scale: 1/4). (a) L5. (b) L6. (c) L7. (d) L8.

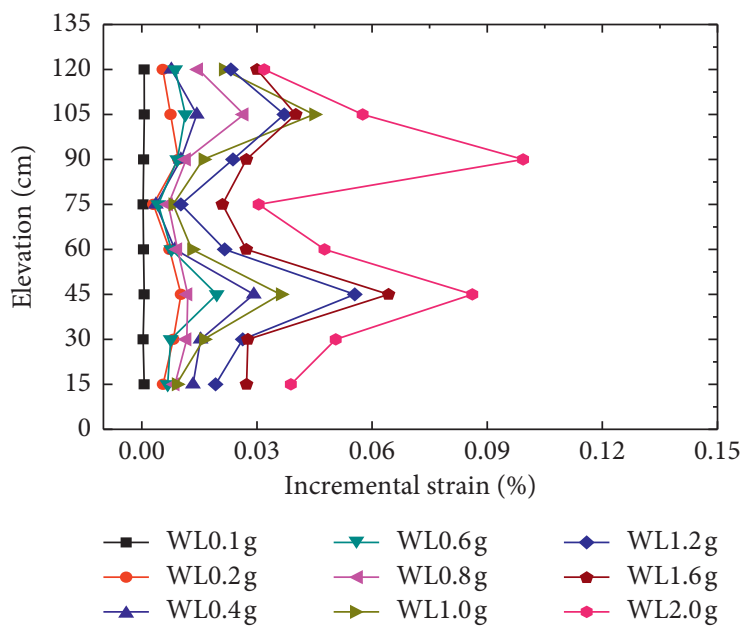

(a)

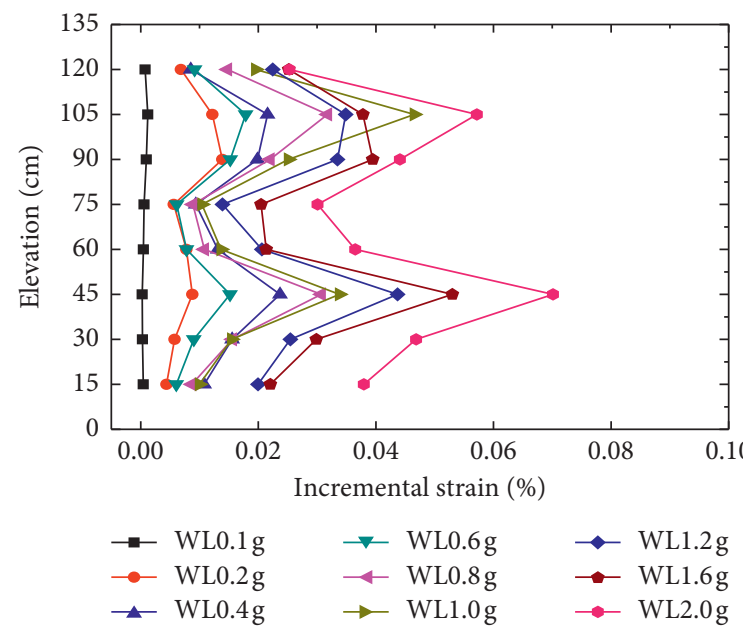

(b)

Figure 16: Continued. 


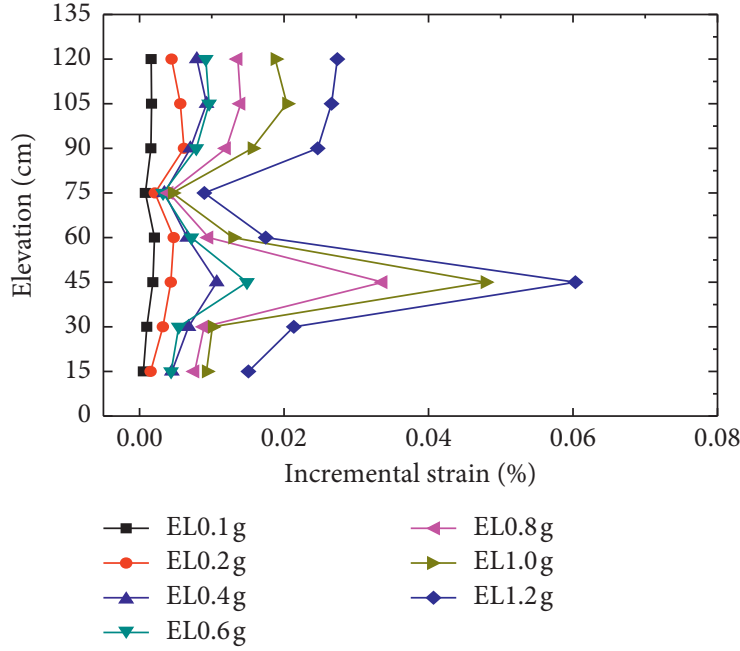

(c)

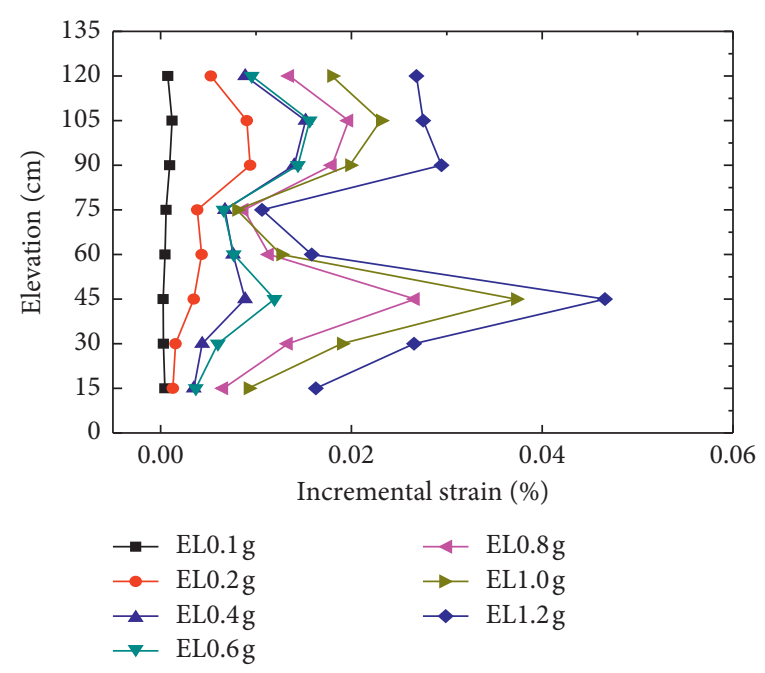

(d)

FIgURE 16: Distribution of strain in T4 and T5 for specimen 2. (a) T4 under WL. (b) T5 under WL. (c) T4 under EL. (d) T5 under EL.

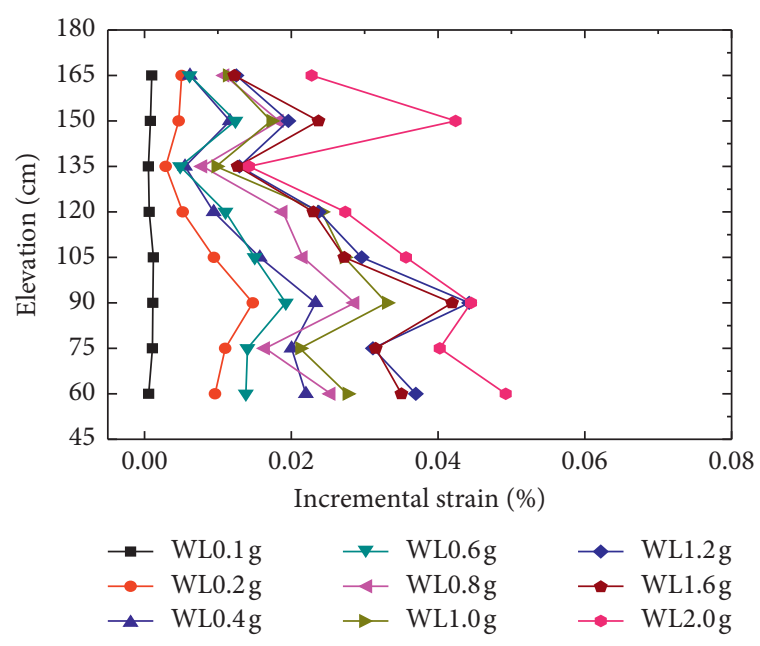

(a)

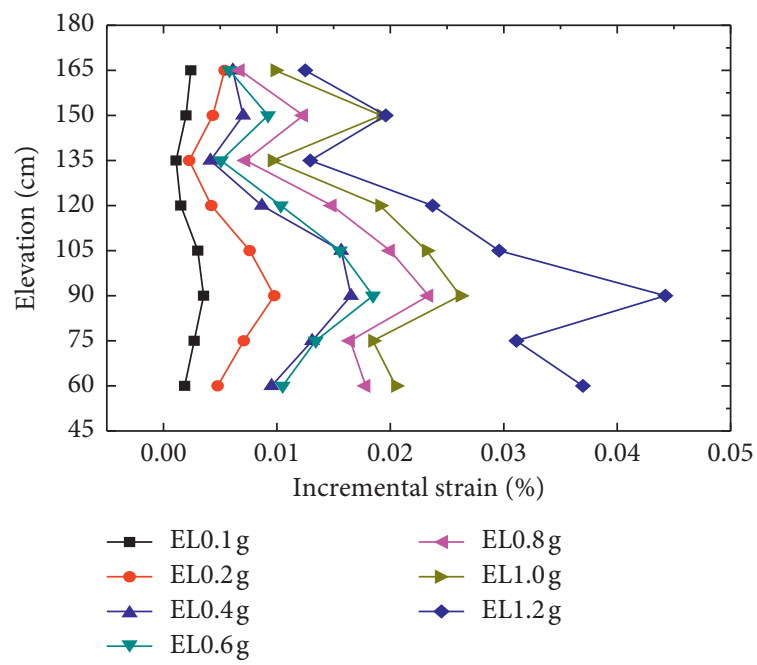

(c)
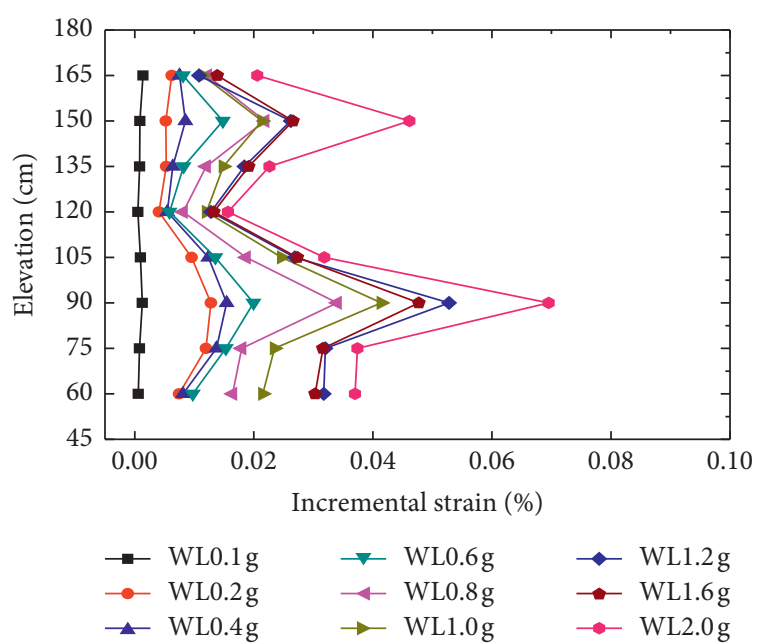

(b)

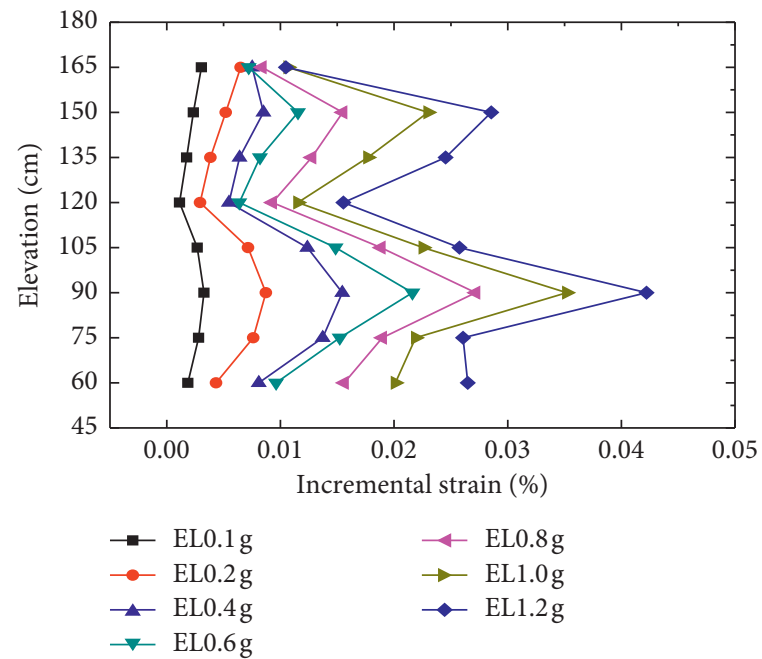

(d)

Figure 17: Distribution of strain in T6 and T7 for specimen 2. (a) T6 under WL. (b) T7 under WL. (c) T6 under EL. (d) T7 under EL. 


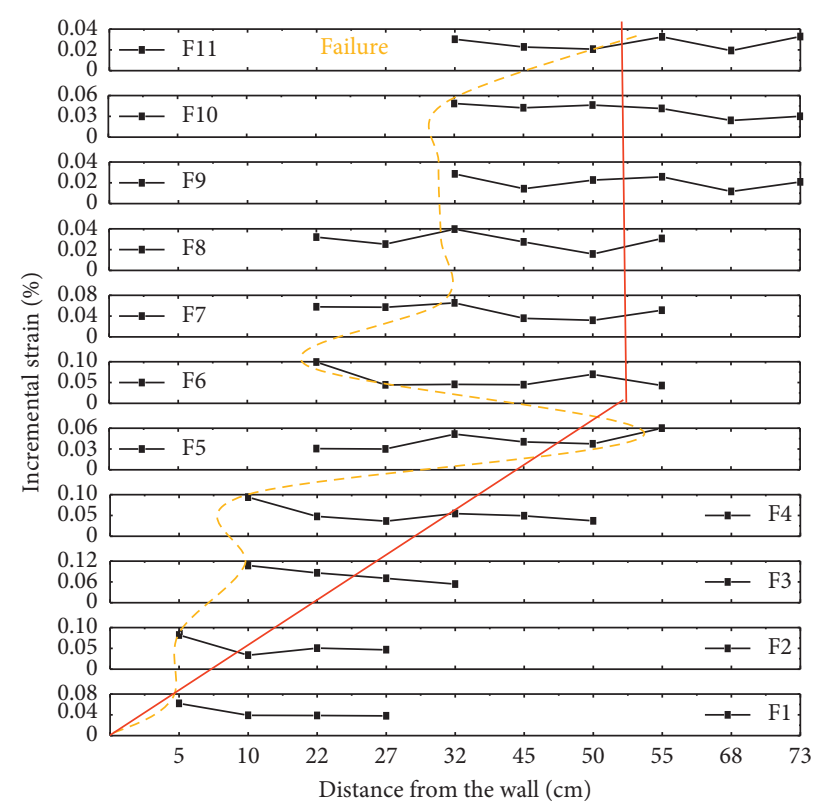

(a)

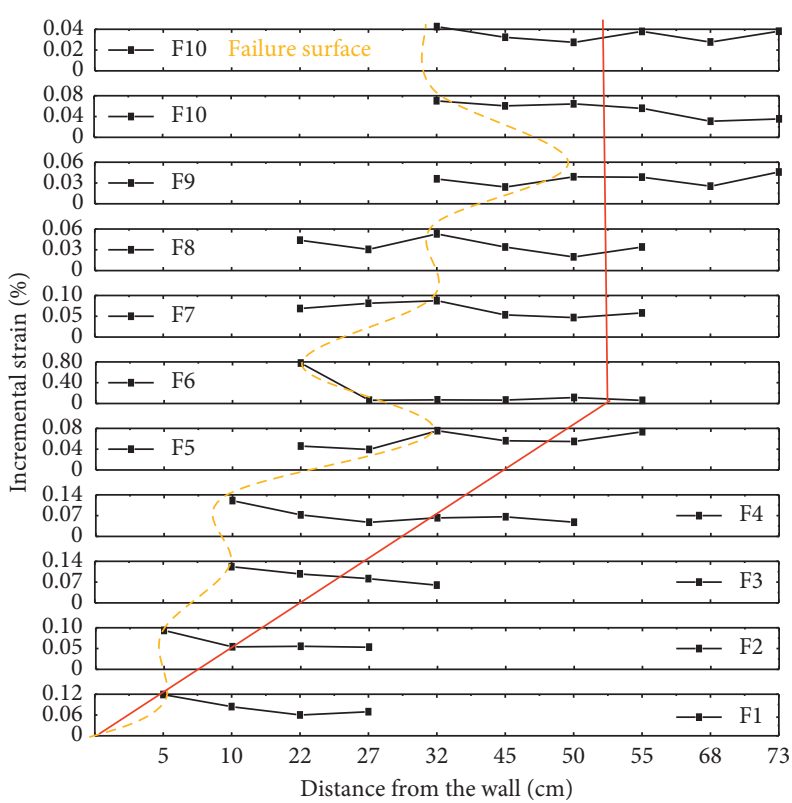

(b)

FIgURE 18: Distribution of strain in reinforcement layers for specimen 2. (a) Case 31. (b) Case 32.

3.6. Potential Failure Surface Calculation Method for Specimen 2. The various calculation methods for the potential failure surface are summarized in Figure 20. It can be observed that although the majority of the maximum measured strain points measured of the reinforcement are on both sides of the log spiral proposed by Lei [3], there are also a few points on the right side of the line. To ensure safety and stability and reduce engineering costs, line 5 (BS8006 surface) is more suitable for obtaining the failure surface formed by the measured maximum strain point of each layer. Therefore, it is suggested that the potential failure surface of the specimen 2 under dynamic motion be selected by BS8006 [11].

\section{Discussions}

Considering the suddenness and uncertainty of the earthquake, it is difficult to understand the behaviour of geogrid RSRW; the shaking table test is performed to study the actual prototype RSRW through the reduced-scale model. However, the test methods and scaling factors need to be considered. In this study, in measuring the location of the failure surface in model tests, other methods, such as inserting coloured sand layers in advance and carefully observing them after the test, would provide more clear and accurate information. It is impossible to record the failure surface during vibration. The author tried to record and observe the trend of the failure surface during the test, laid the layer of blue sand every $15 \mathrm{~cm}$, but the result was not satisfactory. The test method for observing the position of the failure surface during vibration needs to be further studied.

Of the various results offered in the literature, it is difficult to failure of the reinforcement in the shaking table test. So the same geogrid was used in two reduced-scale models, and the geogrid was not scaled. The form of the failure surface for the RSRW is not only mentioned above but also a two-wedge failure surface. Due to the use of the location of maximum strain as a basis for judgment, the twowedge failure surface is not mentioned. Also, the ultimate strain of the reinforcement is generally about $10 \%$, and the measured strain by a strain gauge and an extensometer is within $2 \%$, which is far from the limit. Therefore, the failure surface existing in these planes mentioned above remains to be further explored, and it can be used as a basis for calculation at present.

Specifications for Design of Highway Subgrades [7] (in Chinese) stipulates that the height of RSRW of expressways and first-class highways should not be greater than $12 \mathrm{~m}$, the height of RSRW of second-class and below highway should not be greater than $20 \mathrm{~m}$, and the height of multitiered RSRW should not exceed $10 \mathrm{~m}$. It can be known that the specimens 1 and 2 have different application height ranges. Therefore, specimens 1 and 2 use different model scales and geogrid length. At present, the additional effect of the upper retaining wall to the lower retaining wall is unclear, and the design theory of the multitiered RSRW is not perfect. Therefore, the method of designing the length of the multitiered RSRW needs further take into account.

On comparing the reinforcement strain of different layers in the specimen 1 , it can be observed that the reinforcement strain value of the lower wall is greater than that of the upper wall. This condition may be caused by the fact that the reinforcement of the lower retaining wall is required to bear its load and the upper wall load simultaneously, while the reinforcement of the upper wall is only subjected to its load. If the lower wall is regarded as the RSRW, and the upper wall and backfill are regarded as uniform loads, the research results are consistent with those of Wang et al. [17] 


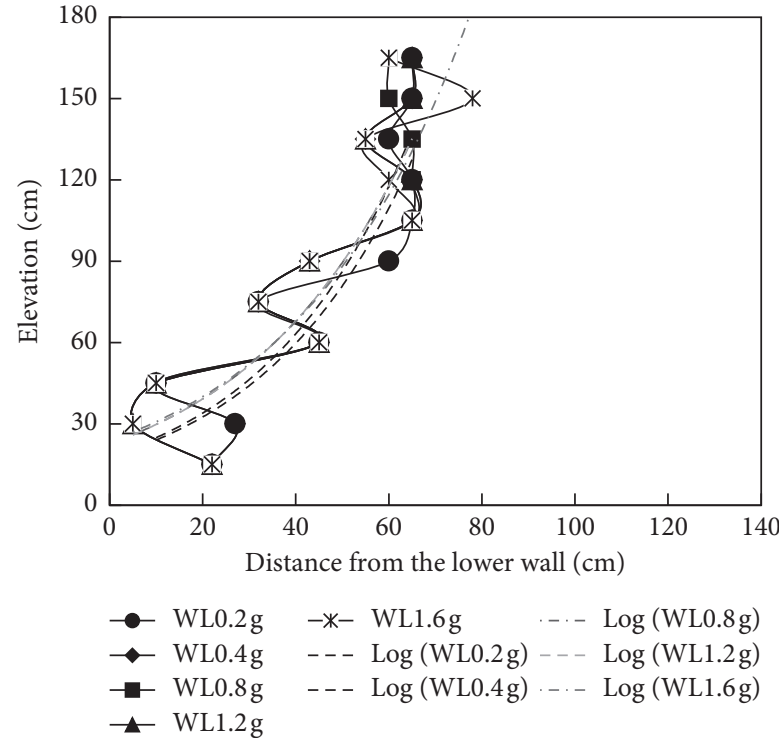

(a)

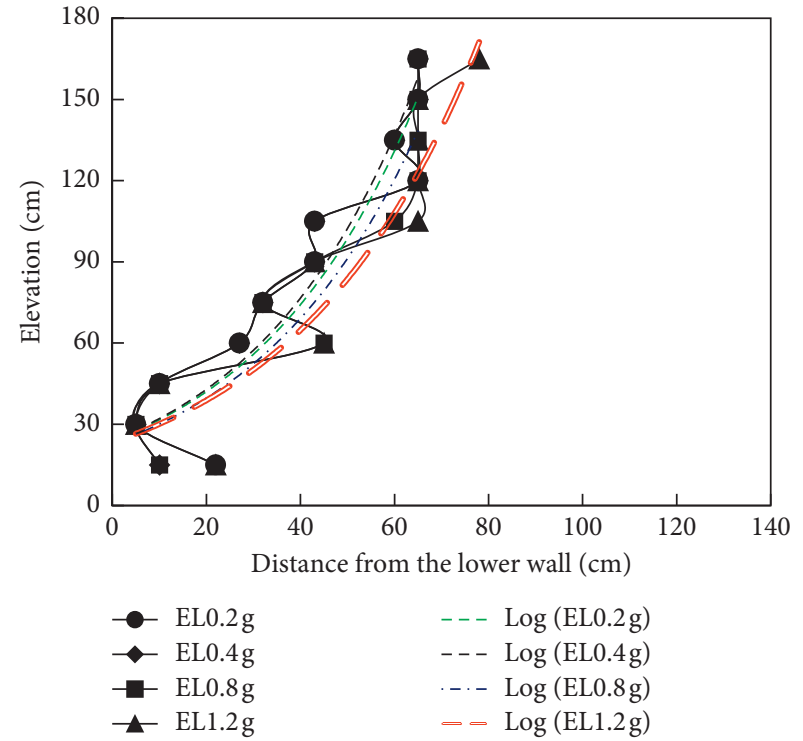

(b)

FIgURE 19: Fitting curve of specimen 1 potential failure surface. (a) WL fitting curve. (b) EL fitting curve.

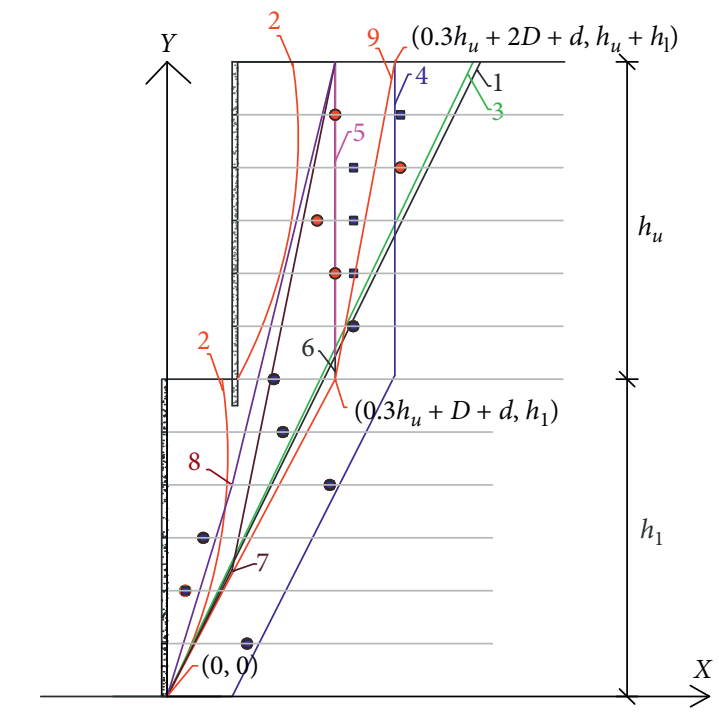

- EL1.2g measured failure point

- WL1.6g measured failure point

1 FHWA surface

2 Lei method

3 Wang fitting curve

4 Zhou surface

Figure 20: Potential failure surface calculation method of specimen 2.

comparing the same vertical position in the specimen 1 . This law is contrary to the displacement distribution of two-tiered RSRW [12]: the strain value at the lower wall is large, the displacement of the lower wall is small, and the strain value at the upper wall is small, the displacement of the upper wall

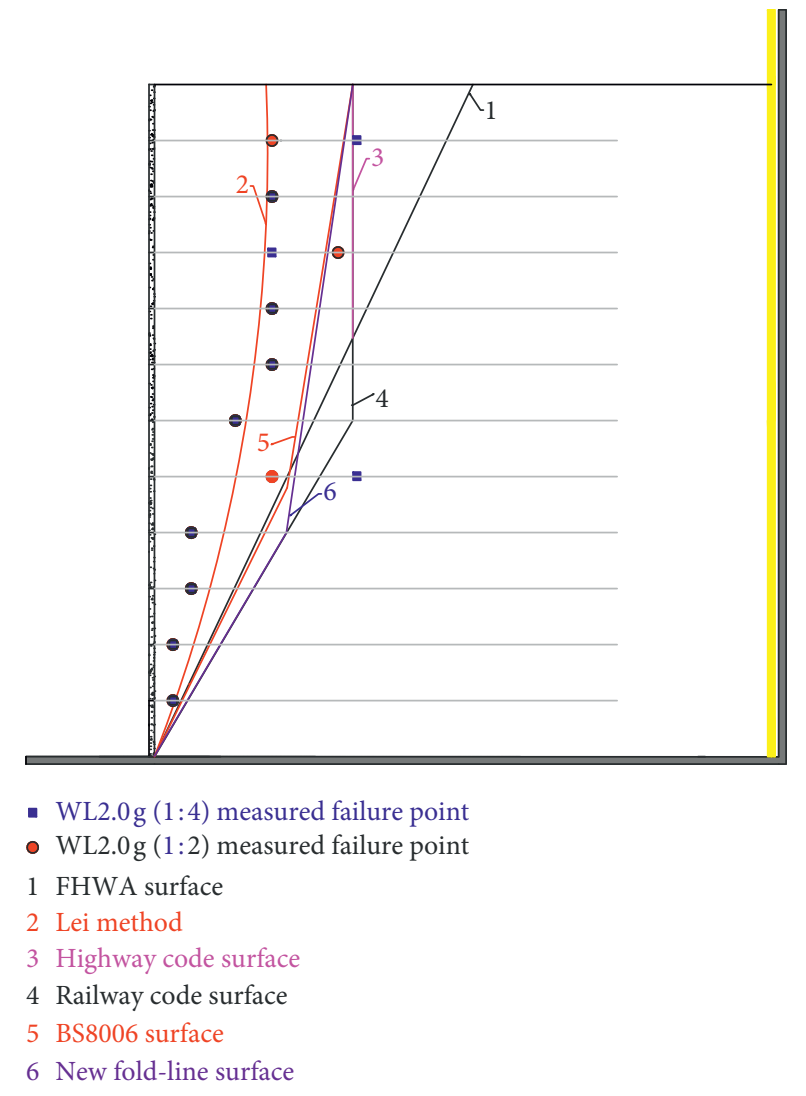

FIGURE 21: Potential failure surface calculation method of specimen 1.

is large. It can be seen that the reinforcement and the modular-block panel cooperate to resist the seismic load. As for how to estimate the magnitude and influencing factors of each part of the earthquake, further research is needed. 
Part of the calculation methods (Geoservice method and CTI method) [14] calculate the deformation of the RSRW using the strain state of the reinforcement under normal use conditions. However, there is no calculation method based on the strain state under seismic condition. Whether the deformation of the retaining wall can be inverted to obtain the strain state of the reinforcement under earthquake motion requires further study.

\section{Conclusions}

To understand the reinforcement stress and potential failure surface distribution of a geogrid RSRW under horizontal seismic loading, the calculation method for the potential failure surface under the dynamic motion of the geogrid RSRW is obtained using the large-scale shaking table tests. The following conclusions could be drawn:

(1) The top model blocks of the specimens 1 and 2 both fall due to the excessive peak acceleration. The model block was damaged because the top two or three blocks are not connected rigidly.

(2) The strain value of specimen 1 tends to increase with the acceleration increase, and the maximum point of the strain value extends into the interior of the soil. The strain values of different layers at the same position are different. The strain value of the lower retaining wall is greater than that strain of the upper retaining wall.

(3) The strain value of the specimen 2 tends to increase as the acceleration increase. When comparing the same-layer strain, the strain law of each layer is consistent. When comparing the strains of different layers at the same location, the strain value law at the same position is nearly the same in all working cases. The strain value of the reinforcement at the lower part of the retaining wall is greater than that at the upper part of the retaining wall.

(4) On comparing the measured maximum curve of the geogrid with the existing calculation method for the potential failure surface, the data show that the existing partial calculation method is conservative.

(5) Based on the various calculation methods for the potential failure surfaces and measured data, a twotiered fold-line failure surface is proposed for specimen 1 while taking into consideration the platform width. And it is advised that the failure surface calculation method of BS8006 be used as the calculation method for the potential failure surface of the specimen 2 under dynamic motion.

\section{Data Availability}

The data used to support the findings of this study are within the supplementary information files.

\section{Disclosure}

This paper and the article "Dynamic Behaviour of reinforced soil retaining wall under horizontal seismic loading" (Li et al. [13]) are the research results of different problems in the same experiment, so there are some similar text.

\section{Conflicts of Interest}

The author(s) declare that there are no conflicts of interest regarding the publication of this paper.

\section{Acknowledgments}

This work was supported by the National Natural Science Foundation of China (grant numbers 51778144), the Earthquake Technology Spark Program of China (grant numbers XH204402), and the Fundamental Research Funds for the Central Universities (grant numbers 20180208).

\section{Supplementary Materials}

Original data analysis is provided in the file named " $\mathrm{Re}$ inforcement strain and potential failure surface." (Supplementary Materials)

\section{References}

[1] K. Rollins, C. Ledezma, and G. Montalva, "Geotechnical aspects of april 1, 2014, M8.2 iquique, Chile earthquake," Technical Report No. GEER-038, Geotechnical Extreme Events Reconnaissance (GEER) Association, Santiago, Chile, 2014.

[2] E. Guler and O. Selek, "Reduced-scale shaking table tests on geosynthetic-reinforced soil walls with modular facing," Journal of Geotechnical and Geoenvironmental Engineering, vol. 140, no. 6, Article ID 4014015, 2014.

[3] S. Y. Lei, "Centrifugal modelling of high double-face reinforced earth retaining wall," Chinese Journal of Rock Mechanics and Engineering, vol. 24, no. 3, pp. 417-423, 2005.

[4] China Plan Press, Technical Code for Application of Geosynthetics: GB/T50290-2014, China Plan Press, Beijing, 2014, in Chinese.

[5] America US Department of Transportation Federal Highway Administration, Design and Construction of Mechanically Stabilized Earth Walls and Reinforced Soil Slopes-Volume I: FHWA-NHI-10-024, America: US. Department of Transportation Federal Highway Administration, Washington, DC, USA, 2009.

[6] X. Wang and L. R. Xu, "Test and analysis of two-step retaining wall reinforced by geogrid," Chinese Journal of Geotechnical Engineering, vol. 25, no. 2, pp. 220-224, 2003.

[7] China Communications Press, Specifications for Design of Highway Subgrades: JTG D30-2015, China Communications Press, Beijing, China, 2015.

[8] China Railway Press, Code for Design on Retaining Structures of Railway Subgrades: TB10025-2006, China Railway Press, Beijing, China, 2006, in Chinese.

[9] X. Huang, G. Xu, and P. Li, "Failure surface and bearing capacity character of combined reinforced gabion retaining wall," China Journal of Highway and Transport, vol. 24, no. 6, pp. 31-38, 2011. 
[10] S. Zhou, C. Wang, G. He et al., "Study on rational model of potential fractured surface for stepped geogrid reinforced soil retaining wall," Journal of Highway and Transportation Research and Development, vol. 24, no. 11, pp. 15-20, 2007.

[11] British Standards Institution, Code of Practice for Strengthened/reinforced Soils and Other Fills: BS 8006-1, British Standards Institution, London, UK, 2010.

[12] X. G. Cai, S. H. Li, and X. Huang, "Shaking table tests on dynamic characteristics of two-stage reinforced soil-retaining wall," China Journal of Highway and Transport, vol. 31, no. 2, pp. 200-207, 2018.

[13] S. Li, X. Cai, H. Xu, L. Jing, X. Huang, and C. Zhu, "Dynamic behaviour of reinforced soil retaining wall under horizontal seismic loading," in Proceedings of IOP Conference Series: Earth and Environmental Science, Chengdu, China, July 2020.

[14] S. Li, X. Cai, L. Jing et al., "Research progress on deformation characteristics of reinforced soil retaining wall," World Earthquake Engineering, vol. 35, no. 4, pp. 114-124, 2019.

[15] S. Iai, "Similitude for shaking table tests on soil-structure-fluid model in $1 \mathrm{~g}$ gravitational field," Soils and Foundations, vol. 29, no. 1, pp. 105-118, 1989.

[16] Y. Zheng, J. S. McCartney, P. B. Shing, and P. Fox, "Physical model tests of half-scale geosynthetic reinforced soil bridge abutments. II: dynamic loading," Journal of Geotechnical and Geoenvironmental Engineering, vol. 145, no. 11, Article ID 4019095, 2019.

[17] L. Wang, G. Chen, and S. Chen, "Experimental study on seismic response of geogrid reinforced rigid retaining walls with saturated backfill sand," Geotextiles and Geomembranes, vol. 43, no. 1, pp. 35-45, 2015.

[18] H. Wang, Research on structural behaviour of geogrid reinforced soil retaining wall under static or dynamic loads, Ph.D. thesis, Beijing Jiaotong University, Beijing, China, 2016.

[19] ASTM, Standard Test Method for Determining Tensile Properties of Geogrids by the Single or Multi-Rib Tensile Method, ASTM, West Conshohocken, PA, USA, 2015.

[20] H. I. Ling, Y. Mohri, D. Leshchinsky, C. Burke, K. Matsushima, and H. Liu, "Large-scale shaking table tests on modular-block reinforced soil retaining walls," Journal of Geotechnical and Geoenvironmental Engineering, vol. 131, no. 4, pp. 465-476, 2005.

[21] R. J. Bathurst, T. M. Allen, and D. L. Walters, "Short-term strain and deformation behavior of geosynthetic wall at working stress conditions," Geosynthetics International, vol. 9, no. 5, pp. 451-482, 2002.

[22] G.-Q. Yang, C. Xu, M.-X. Zhang et al., Geosynthetics Reinforcement Soil Structure Application Guidance, pp. 119-120, China Communications Press Co., Ltd., Beijing, China, 2016, in Chinese. 